Linköping Studies in Science and Technology

Licentiate Thesis No. 1775

\title{
Fatigue Performance of Additive Manufactured Ti6Al4V in Aerospace Applications
}

\author{
Magnus Kahlin
}

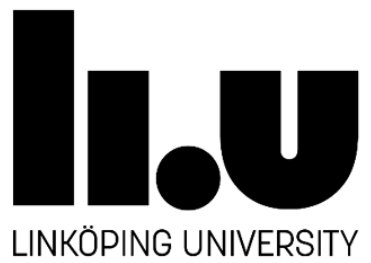

Division of Engineering Materials

Department of Management and Engineering (IEI)

Linköping University, Sweden

Linköping 2017 
Fatigue Performance of Additive Manufactured Ti6Al4V in Aerospace Applications

(C)Magnus Kahlin, 2017

Cover: Photograph Magnus Kahlin, design Magnus Kahlin / Per Lagman

Printed in Sweden by LiU-Tryck, Linköping, Sweden, 2017

ISBN 978-91-7685-538-6

ISSN 0280-7971 


\section{ABSTRACT}

Additive Manufacturing (AM) for metals includes is a group of production methods that use a layer-by-layer approach to directly manufacture final parts. In recent years, the production rate and material quality of additive manufactured materials have improved rapidly which has gained increased interest from the industry to use AM not only for prototyping, but for serial production. AM offers a greater design freedom, compared to conventional production methods, which allows for parts with new innovative design. This is very attractive to the aerospace industry, in which parts could be designed to have reduced weight and improved performance contributing to reduced fuel consumption, increased payload and extended flight range. There are, however, challenges yet to solve before the potential of AM could be fully utilized in aerospace applications. One of the major challenges is how to deal with the poor fatigue behaviour of AM material with rough as-built surface.

The aim of this thesis is to increase the knowledge of how AM can be used for high performance industrial parts by investigating the fatigue behaviour of the titanium alloy Ti6Al4V produced with different AM processes. Foremost, the intention is to improve the understanding of how rough as-built AM surfaces in combination with AM built geometrical notches affects the fatigue properties. This was done by performing constant amplitude fatigue testing to compare different combinations of AM material produced by Electron Beam Melting (EBM) and Laser Sintering (LS) with machined or rough as-built surfaces with or without geometrical notches and Hot Isostatic Pressing (HIP) treatment. Furthermore, the material response can be different between constant amplitude and variable amplitude fatigue loading due to effects of overloads and local plastic deformations. The results from constant amplitude testing were used to predict the fatigue life for variable amplitude loading by cumulative damage approach and these predictions were then verified by experimental variable amplitude testing.

The constant amplitude fatigue strength of material with rough as-built surfaces was found to be $65-75 \%$ lower, compared to conventional wrought bar, in which HIP treatments had neglectable influence on the fatigue strength. Furthermore, the fatigue life predictions with cumulative damage calculations showed good agreement with the experimental results which indicates that a cumulative damage approach can be used, at least for a tensile dominated load sequences, to predict the fatigue behaviour of additive manufactured Ti6Al4V. 


\section{ACKNOWLEDGEMENT}

This research project has been financially supported by Saab Aeronautics, the European commission through the Clean Sky 2 programme and the Swedish Foundation for Strategic Research (SSF) through Industrial PhD 2014, and they are all greatly acknowledged. I would like to express my gratitude to my supervisors professor Johan Moverare at Linköping University and adjunct professor Hans Ansell at Saab Aeronautics for their support and their never ending wisdom which has contributed greatly to the progress in this project. Moreover, I am thankful for the input from the steering committee of this project, which includes professor Sten Johansson at Linköping University and Tomas Ireman, Bertil Franzén and Anders Bredberg at Saab Aeronautics. Many thanks to Patrik Härnman and Annethe Billenius at Linköping University for technical support in the material laboratory and to Lars-Erik Rännar at Mid Sweden University for contributing with test samples.

I also would like to thank my colleagues at both Saab Aeronautics and Linköping University for support and understanding, an industrial $\mathrm{PhD}$ student is torn between industry and academia and can never spend enough time at either place. A special thanks to my colleague Niklas Eriksson at Saab Aeronautics for excellent discussions and for his work with the AM demonstrator part seen on the thesis cover.

I have my parents to thank for many things but for this thesis I especially express my gratitude for the many days of babysitting which made it possible to finish the thesis in time. To my baby boy Oskar, thank you for your encouraging smiles, they mean the world to me. When you will be able to understand this thesis it will be old and probably replaced by new research, since additive manufacturing develops very rapidly, but hopefully it will inspire you to explore science and find out how the world works. Finally, I give all my loving gratitude to my wife Anna, you make the sun rise in the morning and makes me feel special every single day. 


\section{LIST OF PAPERS}

The following papers have been included in this thesis:

I. M. Kahlin, H. Ansell, J.J. Moverare, "Fatigue behaviour of notched additive manufactured Ti6Al4V with as-built surfaces", International Journal of Fatigue 2017, Accepted for publication, doi.org/10.1016/j.ijfatigue.2017.04.009.

II. M. Kahlin, H. Ansell, J.J. Moverare, "Fatigue behaviour of additive manufactured Ti6Al4V, with as-built surfaces, exposed to variable amplitude loading", Submitted for publication 2017.

Contribution to the papers included:

In the above papers I have been the main contributor, performing all experimental work as well as the manuscript writing. In paper II, however, Hans Ansell has performed the fatigue life predictions using cumulative damage calculations.

Papers not included in this thesis:

III. L. Pejryd, P. Karlsson, S. Hällgren, M. Kahlin, "Non-destructive evaluation of internal defects in additive manufactured aluminium", Presented at WorldPM2016, Hamburg (Germany), 2016. 


\section{CONTENTS}

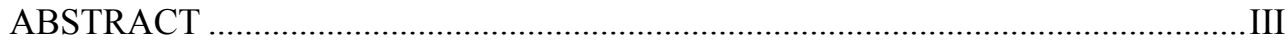

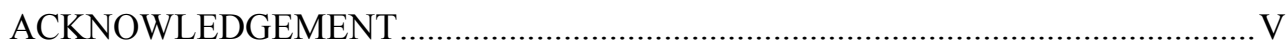

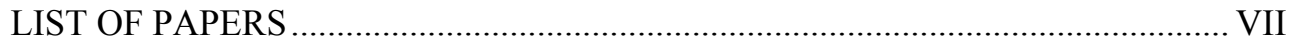

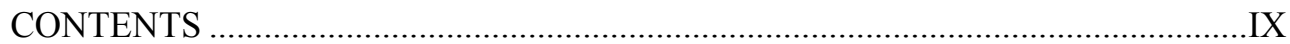

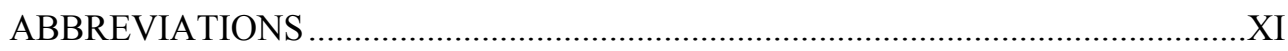

PART I BACKGROUND AND THEORY ......................................1

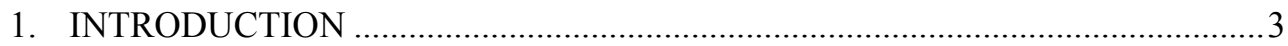

1.1. Introduction to the Research Project........................................................

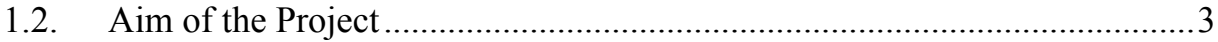

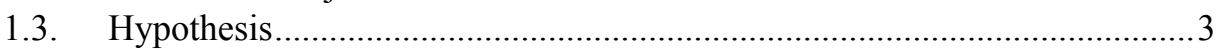

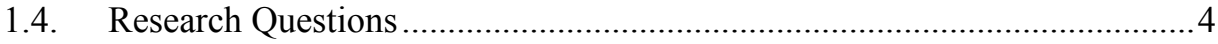

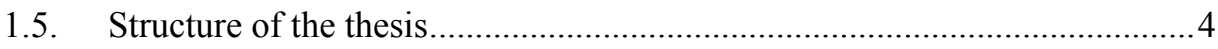

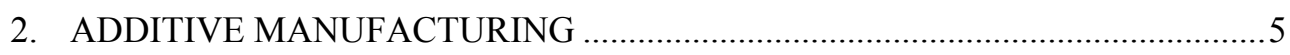

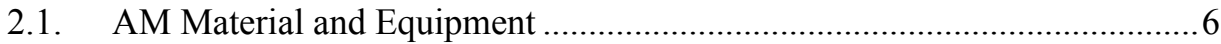

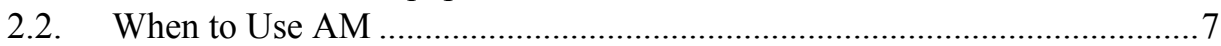

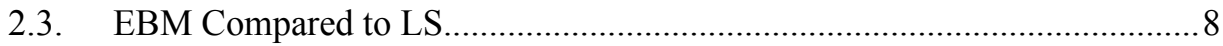

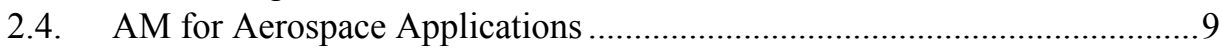

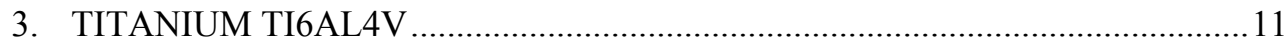

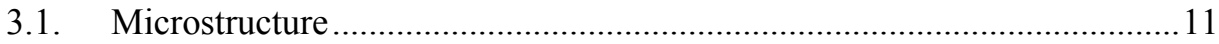

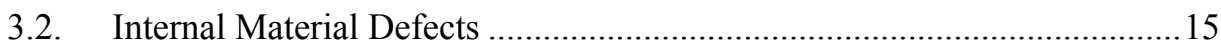

4. MATERIALS AND EXPERIMENTAL METHODS ...........................................19

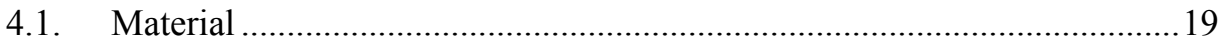

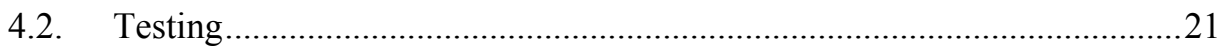

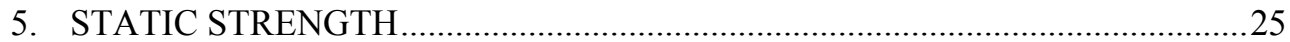

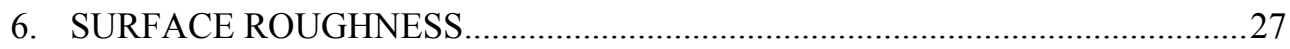

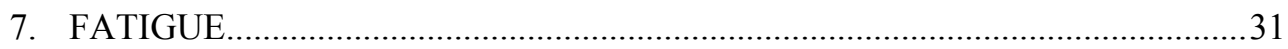

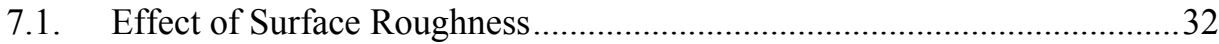

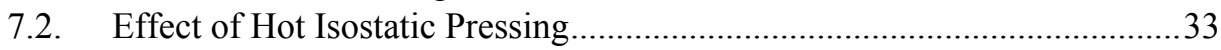

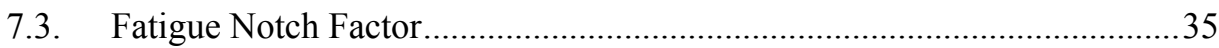




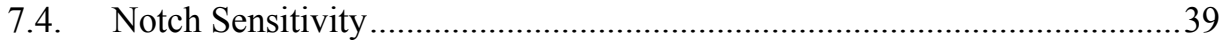

7.5. Variable Amplitude Fatigue ......................................................................... 39

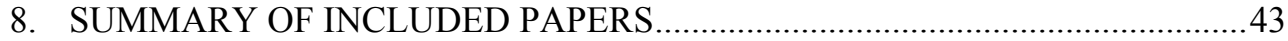

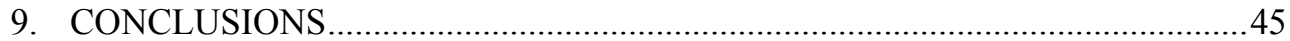

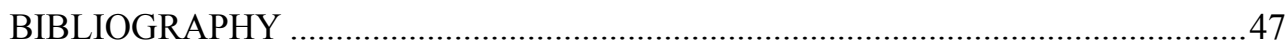

PART II PAPERS INCLUDED...............................................51

Paper I Fatigue behaviour of notched additive manufactured Ti6A14V with as-built surfaces

Paper II Fatigue behaviour of additive manufactured Ti6A14V, with as-built surfaces, exposed to variable amplitude loading..... 


\section{ABBREVIATIONS}

$\begin{array}{ll}\text { AM } & \text { Additive Manufacturing } \\ \text { BD } & \text { Build Direction } \\ \text { EBM } & \text { Electron Beam Melting } \\ \text { HIP } & \text { Hot Isostatic Pressing } \\ \text { LOF } & \text { Lack of fusion } \\ \text { LS } & \text { Laser Sintering } \\ \text { SR } & \text { Stress Relieving }\end{array}$


PART I

BACKGROUND AND THEORY 


\section{INTRODUCTION}

\subsection{Introduction to the Research Project}

This licentiate thesis is a part of the ongoing industrial $\mathrm{PhD}$ project Additive manufacturing: Performance in aerospace applications, which began in January 2015. Saab Aeronautics, the European commission and the Swedish Foundation for Strategic Research (SSF), finance the project that is performed in close collaborations with Saab Aeronautics. Synergies have been found with other research projects through Saab Aeronautics, for example OPTIPAM (Optimized Production Process for Additive Manufacturing/Produktion 2030) and AddMan (Clean Sky 2/Horizon 2020).

Additive manufacturing (AM) have been referred to as the 3:rd industrial revolution, introducing a technological paradigm shift in which the way industrial products are designed and the way logistics is handled will be very different to the existing procedures [1]. Futuristic designs with improved part performance and on-demand manufacturing could be reality in a not too distant future. Additive manufacturing in metal is, however, a relative young field of research in which there still are many challenges to solve before the full potential of AM can be achieved.

\subsection{Aim of the Project}

The aim of the project is to increase the understanding of how AM can be used to produce high performance industrial parts by investigating fatigue and damage tolerance behaviour of titanium Ti6Al4V produced with different AM processes.

By the end of the project, the goal is to have an understanding of which factors that influence the current fatigue behaviour and to have improved the fatigue behaviour through post processing. The goal is further to investigate if existing fatigue life and crack propagation prediction methods gives relevant predictions compared to experimental results.

\subsection{Hypothesis}

AM produced material has different fatigue behaviour compared to wrought material. 


\subsection{Research Questions}

The research questions that are addressed in this licentiate thesis are summarized below:

- What effect have rough as-built AM surfaces, compared to machined surfaces, on fatigue crack initiation properties and what effect has Hot Isostatic Pressing (HIP) on fatigue behaviour for AM material with rough asbuilt surfaces?

- What effect has geometry (geometrical notches), for parts with rough asbuilt surface, on fatigue crack initiation properties?

- Can traditional fatigue life prediction methods be used for AM material?

- Is there any difference in the fatigue behaviour for samples subjected to constant amplitude and variable amplitude loading?

\subsection{Structure of the thesis}

This licentiate thesis consists of two parts:

- Part I: Background and Theory

- Part II: Papers Included

Part I, Background and Theory, cover an introduction of the research project, including aims and research questions, followed by an introduction to additive manufacturing and titanium material. After the introduction, the experimental methods and main findings are presented as well as a summary of the included papers. Finally, the conclusion of the licentiate thesis is given.

Part II, Papers Included, is based on two journal papers, which describe the main research that has been performed in this project. 


\section{ADDITIVE MANUFACTURING}

Additive manufacturing (AM), 3D-printing, is a group of manufacturing processes that have been evolved from rapid prototyping but. After being initially used only for prototyping, the interest in metal AM for serial production has increased rapidly in recent years. In AM, the manufacturer has the possibility to create final components directly from a computer model by adding material layer-by-layer. Moreover, since AM allows for a greater design freedom, designers are no longer restricted to the geometries that can be manufactured by conventional manufacturing, by for example milling or casting. A component can therefore be designed with a complex geometry that can have improved performance or reduced cost compared to the conventional solution [2,3]. AM is still, however, an expensive manufacturing process which is most suitable for small production series and expensive materials, for example titanium and nickel based alloys $[2,4]$.

All AM processes use the layer-by-layer method, in which a small amount of material is added to an existing layer of material which is in contrast to conventional subtracting processes in which material is removed. There are three main techniques for industrial metal AM; Powder Bed Fusion (PBF), Directed Energy Deposition (DED) using wire-feed and DED using blown powder [2]. In addition to this, there are a number of different manufactures of AM equipment for each AM technique and even though the processes are similar each manufacturing equipment gives slightly different material characteristics for the same alloy [5].

This research project has focused on the titanium alloy Ti6Al4V produced with PBF technique, using both Electron Beam Melting (EBM) and Laser Sintering (LS) equipment. EBM and LS processes have the same basic principles, in which a computer model of the component is sliced into thin layers and each layer is manufactured one at a time. A thin layer of pre-alloyed metal powder is spread out on a build platform as schematically illustrated in Figure 1. The material representing the bottom slice of the computer model is thereafter melted, using a laser or an electron beam, leaving all excess powder surrounding the slice unmelted. The build platform is then lowered and the procedure is repeated, in which a new layer of metal powder is spread out and material for the second computer model slice is melted. Several layers of already solidified material are re-melded during the melting of each new layer, fusing the layers together to a solid bulk material as illustrated by the thermal profile in Figure 2. Additional layers are added until the full geometry of the final component is completed [3]. 


\section{Laser or Electron Beam}

New powder spread out

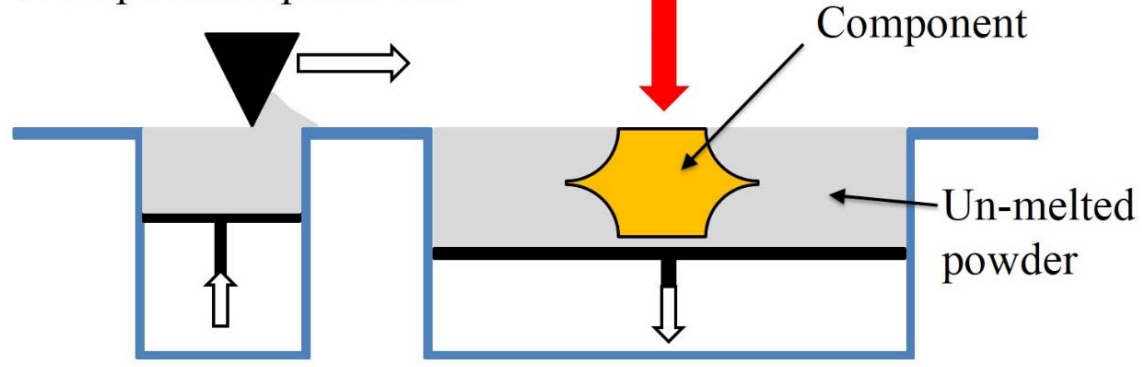

Figure 1. Schematic illustration of a Powder Bed Fusion process.

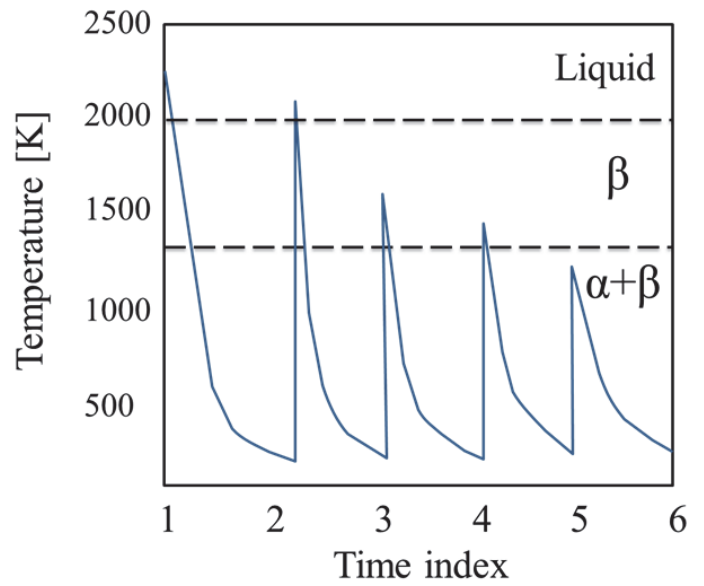

Figure 2. Schematic thermal profile of a single layer of Ti6Al4V with repeated heating during AM, adapted from [2]

\subsection{AM Material and Equipment}

A variety of AM powder bed techniques are available in which, to date, Arcam has the only EBM based systems. Different process parameters are needed for different materials and not all materials are available for all processes. An overview of commercially available alloys and examples of AM powder bed systems are presented in Table 1. New AM techniques and equipment are constantly developed and more materials are added to each process. Therefore, a summary of existing equipment is very fast outdated. The terminology "Laser sintering" refers to any PBF process that use a laser to melt powder particles according ISO/ASTM 52900. Moreover, according to ISO/ASTM 52900, the term "sintering" is used by historical reasons and is a misleading name since the AM process 
involves partial or fully melted powder in contrast to the traditional powder metal sintering.

Table 1. Examples of AM powder bed technologies and equipment. EBM= Electron Beam Melting, LS= Laser Sintering

\begin{tabular}{|c|c|c|c|}
\hline AM Suppliers and Systems & Technique & $\begin{array}{l}\text { Build volume } \\
(\mathrm{mm})\end{array}$ & Materials \\
\hline ARCAM (A2X) [6] & \multirow{2}{*}{ EBM } & $200 \times 200 \times 380$ & \multirow{2}{*}{$\begin{array}{l}\text { Ti6A14V, Ti6A14V ELI } \\
\text { CP Ti, CoCr, IN718 }\end{array}$} \\
\hline ARCAM (Q20plus) [6] & & $\varnothing 350 \times 380$ & \\
\hline EOS (M290) [7] & \multirow{2}{*}{ LS } & $250 \times 250 \times 325$ & \multirow{2}{*}{$\begin{array}{l}\text { Ti6A14V, Ti6Al4V ELI, } \\
\text { AlSi10Mg, CoCr, MS1, } \\
\text { HX, IN625, IN718, stain- } \\
\text { less steels }\end{array}$} \\
\hline EOS (M400) [7] & & $400 \times 400 \times 400$ & \\
\hline $\begin{array}{l}\text { Concept laser LaserCusing (M2) } \\
\text { [8] }\end{array}$ & \multirow{2}{*}{ LS } & $250 \times 250 \times 280$ & \multirow{2}{*}{$\begin{array}{l}\text { AlSi10Mg, Ti6Al4V, } \\
\text { Ti6Al4V ELI, CP Ti, } \\
\text { IN718, IN625, bronze, } \\
\text { stainless steels }\end{array}$} \\
\hline $\begin{array}{l}\text { Concept laser LaserCusing (X } \\
\text { line 2000R) [8] }\end{array}$ & & $800 \times 400 \times 500$ & \\
\hline SLM Solutions (SLM 500) [9] & \multirow[b]{2}{*}{ LS } & $500 \times 280 \times 365$ & \multirow{2}{*}{$\begin{array}{l}\text { Ti6Al4V ELI, Ti6A17Nb, } \\
\text { AlSi-alloys, CoCr, HX, } \\
\text { IN625, IN718, IN939, } \\
\text { stainless steel }\end{array}$} \\
\hline SLM Solutions (SLM 280 2.0) [9] & & $280 \times 280 \times 365$ & \\
\hline Renishaw (AM 500M) [10] & \multirow[b]{2}{*}{ LS } & $250 \times 250 \times 350$ & \multirow{2}{*}{$\begin{array}{l}\text { Ti6A14V ELI, } \\
\text { AlSi10Mg, CoCr, IN625, } \\
\text { IN718, stainless steel }\end{array}$} \\
\hline Renishaw (AM 400M) [10] & & $250 \times 250 \times 300$ & \\
\hline
\end{tabular}

\subsection{When to Use AM}

AM can contribute to industrial parts that are both lighter in weight and cheaper to produce compared to parts produced with conventional manufacturing methods. In addition to this, complex geometries that would be very difficult and expensive to produce with conventional manufacturing methods can be manufactured without increased cost with AM.

AM is not, however, beneficial for all applications and to have the potential advantages, a suitable application must be considered. Frazier [2] has summarized the factors favouring a business case with AM compared to conventional manufacturing presented in Table 2. AM is mostly favoured, according to Frazier, for small production lots with a breakeven point between $90-175$ parts as illustrates by Figure 3 .

AM is not a low-cost production method so it is not favourable for AM to compare the recurring cost for a part manufactured with AM to the same geometry manufactured with conventional manufacturing. To fully take advantage of the 
potential of AM other aspects need to be considered e.g. complex geometries, lower lead times, reduced weight through optimized AM design [11] and reduced assembly through integration of several parts into one. There are also possibilities to increase the customer value by customized products or integrating additional functions in the part.

Table 2. Factors favouring AM vs conventional manufacturing. Source [2]

\begin{tabular}{|l|l|}
\hline Favor AM & Favor Conventional Manufacturing \\
\hline Low production volumes & Large production volumes \\
\hline High material cost & Low material costs \\
\hline High machining cost & Easily processed/machined materials \\
\hline Capital investment & Centralized manufacturing \\
\hline Logistics costs & \\
\hline Transportation costs & \\
\hline Prototyping & \\
\hline
\end{tabular}

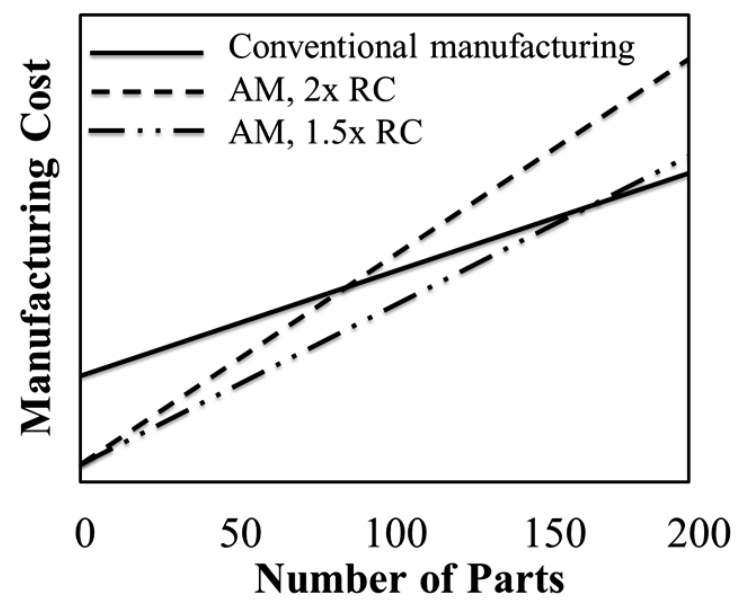

Figure 3. Low volume business case for conventional fabrication methods vs AM with two different Recurring Costs (RC), adapted from [2].

\subsection{EBM Compared to LS}

EBM and LS are both PBF processes with the same basic principles. However, even though the processes are similar, the procedures differ in some important aspects which results in different properties of the AM component depending on which AM equipment that is used. The major differences between EBM and LS processes are presented in Table 3. The EBM process is performed in vacuum using a pre-heated powder bed which effectively reduces the residual stresses in the final part [12]. LS processes are generally performed in non-heated build chambers with argon gas environment [12]. Moreover, the LS non-heated build 
chambers generate much higher residual stresses in the material, compared to EBM material, and post stress relieving heat treatment is therefore necessary for LS material [5].

Another important difference between the processes is that LS processes uses smaller size powder particles and thinner build layers, compared to EBM, which result in better surface finish for LS parts, i.e. a lower surface roughness [13].

Table 3. Electron Beam Melting (EBM) process compared to laser sintering (LS) .

\begin{tabular}{|l|l|l|}
\hline & EBM & LS \\
\hline Environment & Vacuum [6] & Inert gas [7] \\
\hline Heated powder bed & Yes, approx. 700 ${ }^{\circ} \mathrm{C}[6]$ & No* [15] \\
\hline Layer thickness & $50-70 \mu \mathrm{m} \mathrm{[6]}$ & $20-30 \mu \mathrm{m} \mathrm{[7]}$ \\
\hline Powder size & $45-100 \mu \mathrm{m}[6]$ & $25-45 \mu \mathrm{m} \mathrm{[14]}$ \\
\hline
\end{tabular}

${ }^{*}$ Generally, not heated to high temperatures. Powder bed kept at $90^{\circ} \mathrm{C}[16]$

\subsection{AM for Aerospace Applications}

Additive manufactured components are generally considered to have great potential for aerospace applications. The performance of aerospace components can be improved by new innovative design solutions that now are possible with AM. Light weight design is one good example of improved performance that would be appealing to the aerospace industry. A reduced weight could for an aircraft, like for example the Saab JAS 39 Gripen in Figure 4, contribute to extended flight range, increased payload and reduced fuel consumption.

Even though AM is an expensive manufacturing method it could contribute to reduced costs through reducing assembly and machining operations. In addition, welding and other joining operations can be eliminated by integration of several parts into one AM part [17]. Moreover, reduced machining by producing AM parts with final or near-net-shape geometry would considerably reduce the amount of machining which is an expensive for tough materials, like for example titanium and nickel base alloys [4]. 


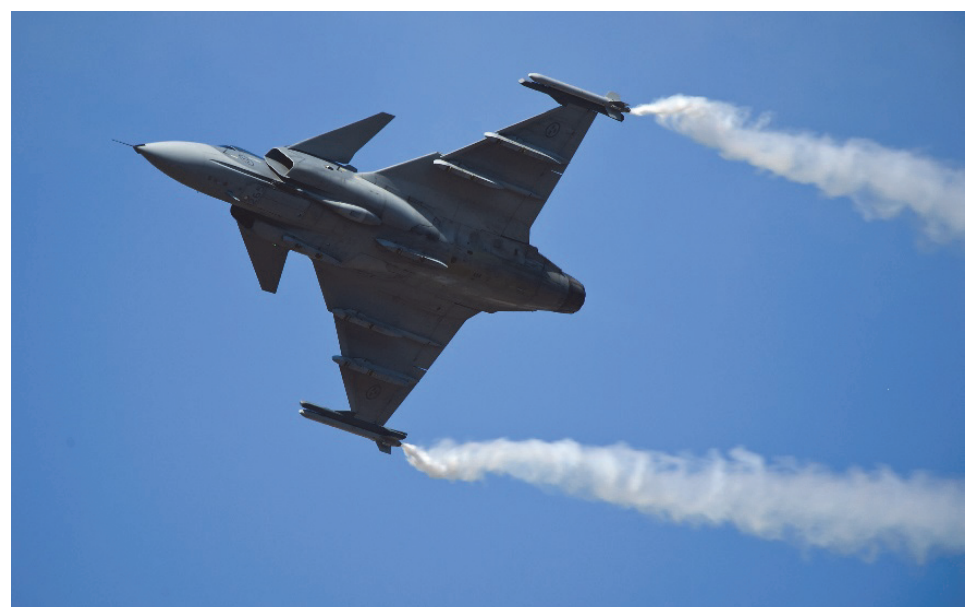

Figure 4. The Saab JAS 39 Gripen fighter. Photo Frans Dely. Copyright Saab AB.

There are however still a number of challenges yet to be solved before AM can be fully utilized in aerospace applications, a few of them are listed below [18]:

- The variation in material properties and quality between different AM equipment must be understood and controlled.

- Qualification methods adapted to AM must be established.

- There is a need for new reliable non-destructive testing (NDT) methods to enable inspection of aerospace AM parts for critical flaws and defects.

- Design guide lines for AM need to be established to be able to use innovative AM design to reduce weight

- Improved fatigue properties for AM materials through better surface finish are needed.

- Simulation models are needed to predict properties and microstructure for an AM process.

- New alloys especially adapted for AM processes should be developed 


\section{TITANIUM TI6AL4V}

This chapter provides general information about the titanium alloy Ti6Al4V addressed in this thesis. Alloy Ti6Al4V is to date the most widely used titanium alloy by far and correspond to more than $50 \%$ of the annual titanium production [19]. Aerospace and medical industry are two of the major customers and in 2006 , aerospace used $44 \%$ of the world production of titanium in which Ti6A14V was the most commonly used alloy [20].

When it comes to metal AM, Ti6Al4V is the alloy that have been investigated the most, which can be attributed to a large range of possible business cases of advanced industrial parts with low production volumes [2]. Additive manufactured Ti6Al4V has the same chemical composition, see Table 4, as Ti6Al4V produced from conventional production forms like for example castings, bars or forgings. However, material behaviour for AM Ti6Al4V can still be very different compared to the behaviour of Ti6Al4V from conventional product forms. The different behaviour can both be attributed to differences in microstructure [12,13,21] but also due to effects of the rough as-built AM surface which affects both fatigue behaviour $[12,21-23]$ and static properties $[21,22,24]$.

Table 4. Nominal chemical composition, according to ASTM F2924-14, for Ti6A14V manufactured by powder bed fusing

\begin{tabular}{|l|l|l|l|l|l|l|l|l|l|l|}
\hline & $\mathrm{Al}$ & $\mathrm{V}$ & $\mathrm{Fe}$ & $\mathrm{O}$ & $\mathrm{C}$ & $\mathrm{N}$ & $\mathrm{H}$ & $\mathrm{Y}$ & Other & $\mathrm{Ti}$ \\
\hline $\begin{array}{l}\text { Min, } \\
\%\end{array}$ & 5.50 & 3.50 & - & - & - & - & - & - & - & \\
\cline { 1 - 1 } $\begin{array}{l}\text { Max, } \\
\%\end{array}$ & 6.75 & 4.50 & 0.30 & 0.20 & 0.08 & 0.05 & 0.015 & 0.005 & 0.40 & remainder \\
\hline
\end{tabular}

\subsection{Microstructure}

The AM PBF production methods are complex and includes both layer-by-layer manufacturing and repeated heating, see Figure 2, of the material [2]. The heat cycle, that includes both heating and cooling, is rapid and grain formation is therefore very fast even though the grains do not have time to grow further due to the quick cooling, in which cooling rates of $10^{4} \mathrm{~K} / \mathrm{s}$ have been reported for LS [2]. During each heat cycle, the laser or electron beam melts simultaneously both a new layer of un-melted powder and several layers of already solidified material. This gives a continuous microstructure across the layers and the growth of columnar grain structure is promoted in the vertical building direction [2]. 


\subsubsection{Conventional Produced Ti6Al4V}

The microstructure of Ti6Al4V from conventional product forms is achieved by refinement of the grains during cooling from the $\beta$-phase or the $\alpha+\beta$ phase region followed by ageing heat treatment to dissolve the martensite formed at quenching. During slow cooling from the $\beta$-region the microstructure start to form $\alpha$-phase below the $\beta$-transus $\left(980^{\circ} \mathrm{C}\right)$. The $\alpha$ form as plates and together with the remaining $\beta$-phase it forms a Widmanstätten structure which is illustrated in Figure 5 [25].

When cooled quickly from temperatures above the $\beta$-transus $\left(980^{\circ} \mathrm{C}\right)$ the $\beta$-phase could decompose to martensitic $\alpha^{\prime}$ or $\alpha^{\prime \prime}$ structure with only a small amount of remaining $\beta$. The $\beta$-phase can remain in the structure even after rapid cooling since the end of the martensitic transformation, $\mathrm{M}_{\mathrm{f}}$, is below room temperature $\left(<25^{\circ} \mathrm{C}\right)$ for this alloy and not all $\beta$ is therefore transformed to $\alpha$ ' or $\alpha$ '. Subsequent heat treatment to achieve a more ductile material is common by, for example mill annealing at $730^{\circ} \mathrm{C}$ for $4 \mathrm{~h}$, which gives a microstructure with globular crystals of $\beta$ within an $\alpha$-matrix [25].

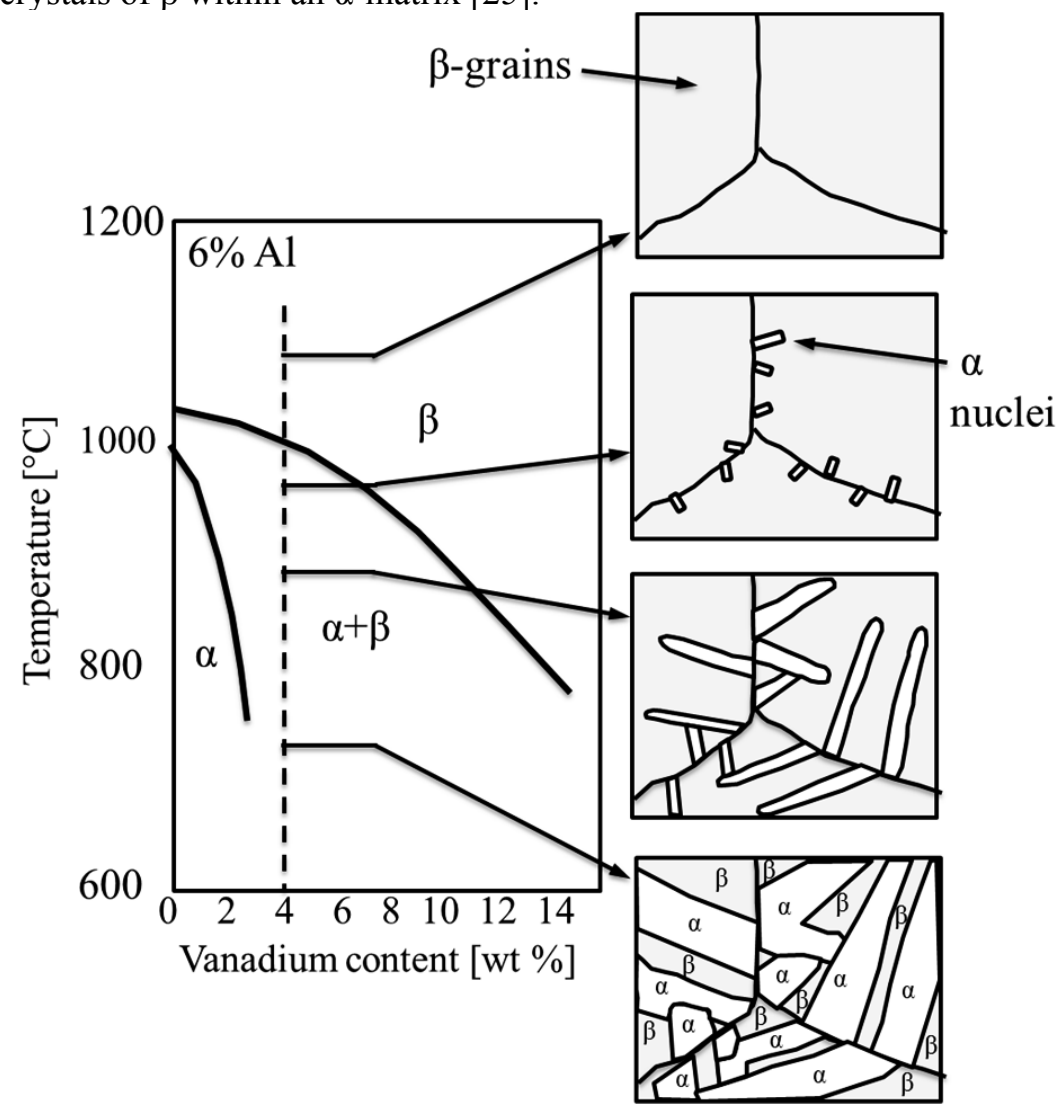

Figure 5. Phase diagram for Ti6A14V and schematic microstructure at intermediate temperatures during slow cooling from a temperature above the $\beta$-transus. The final microstructure has plates of $\alpha$ (white) separated by $\beta$-phase (dark). Adapted from [25] 


\subsubsection{EBM Produced Ti6Al4V}

Ti6Al4V produced by EBM has a pronounced columnar grain structure in the vertical building direction that is continuous through multiple building layers as illustrated by Figure $6[11,26]$. The microstructure generally consists of $\alpha$ (hcp) + $\beta$ (bcc) microstructure [12] and has elongated columnar (epitaxial) $\beta$-grains with a secondary $\alpha$-phase that has grown from prior $\beta$-grain boundaries $[11,26]$. The $\alpha$-phase is acicular (needle like) or plate like and has generally a fine and evenly distributed Widmanstätten (basket weave) structure [26]. The microstructure of EBM material subjected to HIP has been found to be courser but otherwise similar to the microstructure of EBM without heat treatment which is illustrated in Figure 7 [26]. The rough as-built AM surface consists of partially melted powder grains that are attached to the surface. These grains have a continuous microstructure with the bulk material which can be seen in Figure 8 .

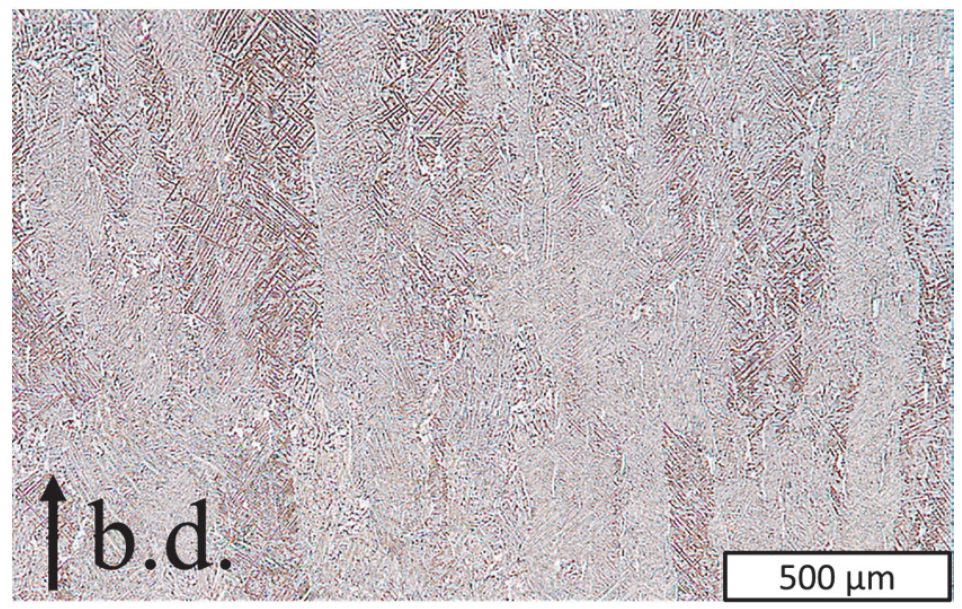

Figure 6. Columnar grains of EBM Ti6Al4V material, b.d.= build direction.
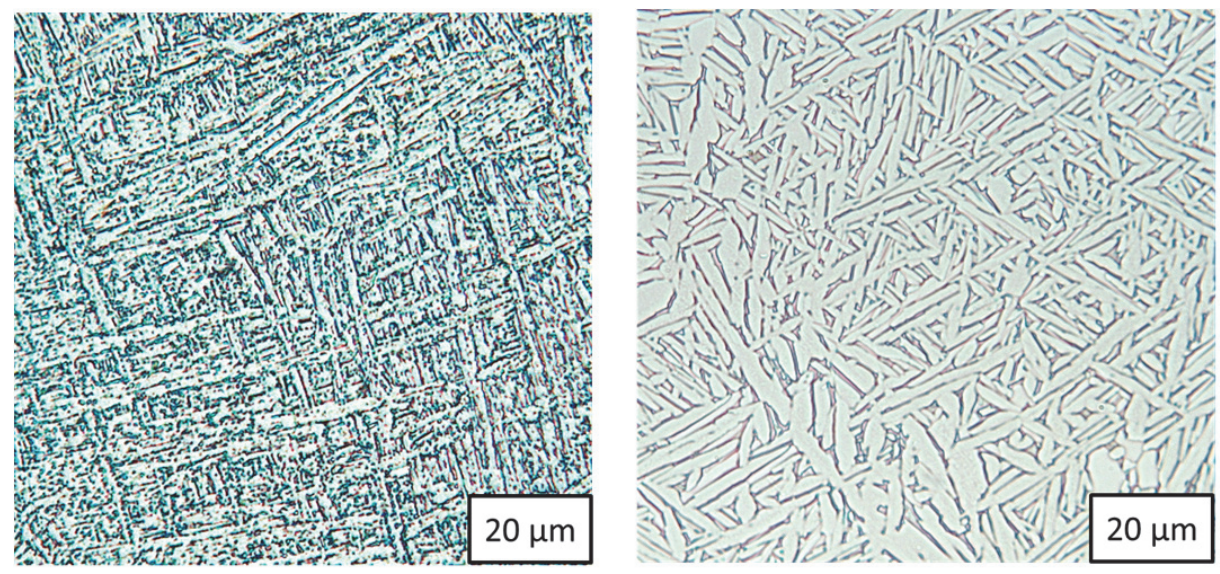

Figure 7. Microstructure of EBM Ti6A14V as-built (left) and HIP:ed (right). 


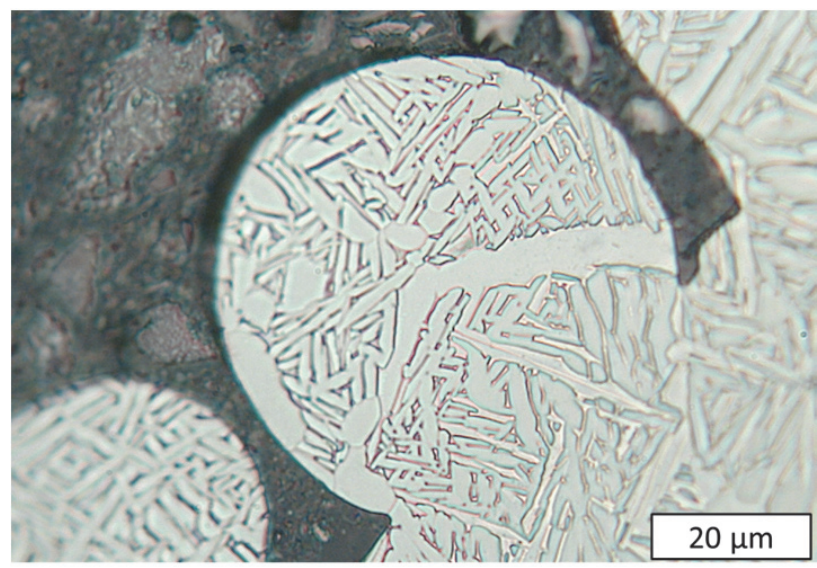

Figure 8. Partially melted grains attached to the surface with continuous microstructure continuing into the bulk material.

\subsubsection{LS Produced Ti6Al4V}

Ti6Al4V produced with LS show somewhat different microstructure characteristics compared to EBM material. The higher cooling rates of LS give a finer microstructure, compared to EBM material, but the high rate also contributes to considerable higher residual stresses if no post heat treatment is performed [15].

Similar to the EBM microstructure, the LS Ti6Al4V has a pronounced columnar grain structure in the vertical building direction that is continuous through several building layers $[15,21,27]$. If no post heat treatment is performed for LS material, the microstructure generally consists of $\alpha-\alpha^{\prime}$ (martensite) microstructure [12]. The columnar grains are filled with $1-2 \mu \mathrm{m}$ wide martensitic laths that are transformed from prior $\beta$-grain boundaries [13]. LS material that is post heat treated with stress relieving, at $700-730^{\circ} \mathrm{C}$ for $1-2 \mathrm{~h}$, can either have martensitic $\alpha^{\prime}$ microstructure or a mixture of $\alpha+\beta$ if the temperature exposure is large enough $[21,28]$. If the $\mathrm{LS}$ material is annealed at higher temperatures $\left(900^{\circ} \mathrm{C} 2 \mathrm{~h}+700^{\circ} \mathrm{C}\right.$ $1 \mathrm{~h})$, the $\alpha^{\prime}$ is transformed to $\alpha+\beta$ microstructure [21]. 


\subsection{Internal Material Defects}

\subsubsection{Porosity}

Spherical microporosity, see Figure 9, in both EBM and LS material originates generally from the gas atomized powder which could contain entrapped microporosity of argon gas bubbles [26,29]. However, if appropriate AM process parameters are used a pore free material is generally achieved with a relative density above $99 \%$ [30].

There are different methods for porosity measurements which all can give measurement process induced variations of the results according to Kasperovich et al. [21]. Analysis of etched surfaces in 2D can give misleading results due to expansion of the pores by the etchant. Non-etched surface analysis in 2D can give misleading results due to closure of small pores by smearing of material during sample preparation. Computed Tomography (CT) scanning used for 3D analysis can give misleading results with non-detectable pores, if the pores are smaller than the resolution. Moreover, Archimedes technique can greatly overestimates the relative density and give large deviations $\pm 0.4 \%$ which is very large when evaluating relative densities of about 99\% [21]. Kasperovich et al. [21] concluded that the $3 \mathrm{D}$ analysis most likely gives the most accurate determination of the internal porosity.

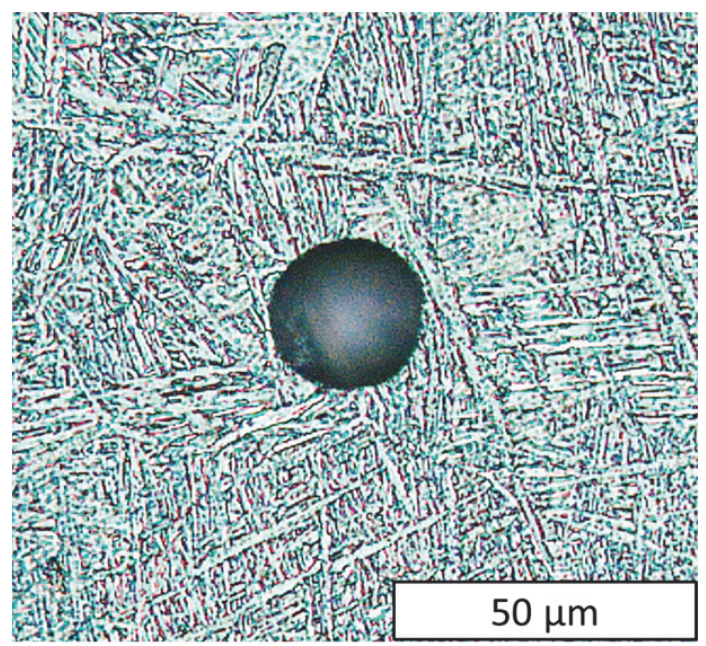

Figure 9. Spherical micro-porosity in as-built EBM Ti6Al4V material. 


\subsubsection{Lack of Fusion (LOF)}

The most severe internal defect in AM materials, from a fatigue point of view, is Lack of Fusion (LOF), see Figure 10, which is primarily formed between the building layers [29]. LOF defects are generally created if there is insufficient energy to properly melt and fuse the new layer with the previous layer during the manufacturing process [29]. Other factors that can promote LOF could be nonoptimal focus calibration of the beam, unsuitable parameters of beam current and scan speed, non-optimal settings for powder deposition or powder with to high content of contaminations.

LOF is generally aligned perpendicular to the building direction and forms primarily along the interlayer boundaries in the interface region between the material melted with contour-parameters and material melted with hatching [29].

Three types of LOF have been identified by Liu et al. [29]; Type-I is a "separated" surface with un-melted powder particles, Type-II is a "separated" surface without un-melted powder particles and Type-III is a narrow and long shape with un-melted powder particles. Type-I and Type-II LOF occurs often in vertically built samples while Type-III only occurs in horizontally built samples. The LOF defects act both as stress concentrations and reduces the load-bearing area when samples are loaded in the building direction (perpendicular to the layer). This reduce the fatigue and static strength in building direction as well as the elongation to fracture [31]. For fatigue specimens with machined surfaces the fatigue cracks generally initiated from internal LOF and therefore an elimination of LOF can, through process optimization or HIP treatment, increase the fatigue life [29].

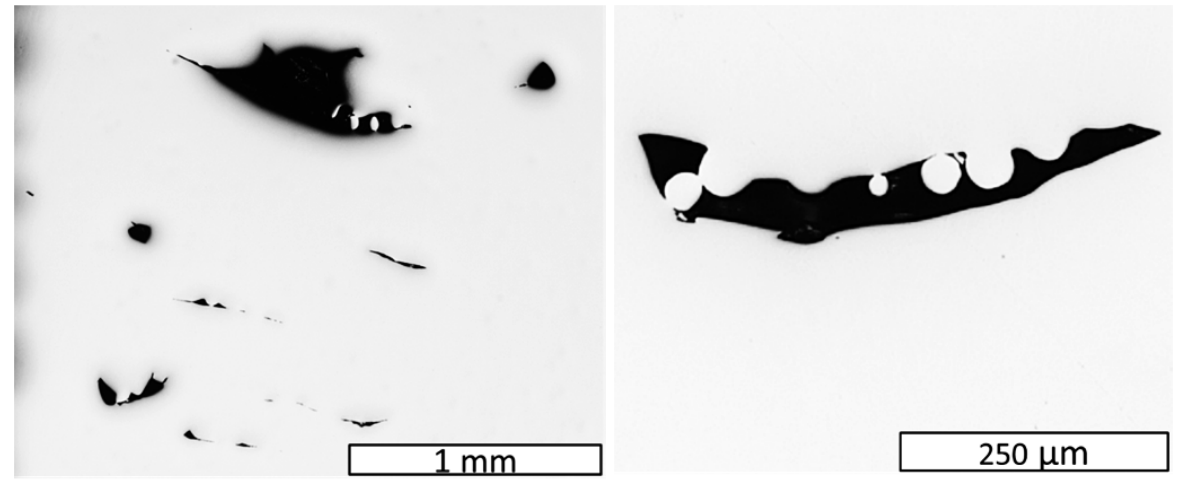

Figure 10. Lack of fusion (LOF), in EBM for Ti6Al4V, located between building layers. Partially melted powder grains are visible. 


\subsubsection{Effect of Hot Isostatic Pressing (HIP)}

The effect of HIP is illustrated in Figure 11, in which material with and without HIP is compared. The EBM material without HIP, investigated in the present study, had a large amount of gas pores and LOF while the non-HIP LS material only had a minor amount of pores and LOF. I contrast, after HIP all internal pores and LOF were eliminated, for both LS and EBM material, and only occasional LOF were visible just below the surface. This indicates that these LOF are directly connected to the surfaces since fully enclosed voids would be needed for HIP to be effective.
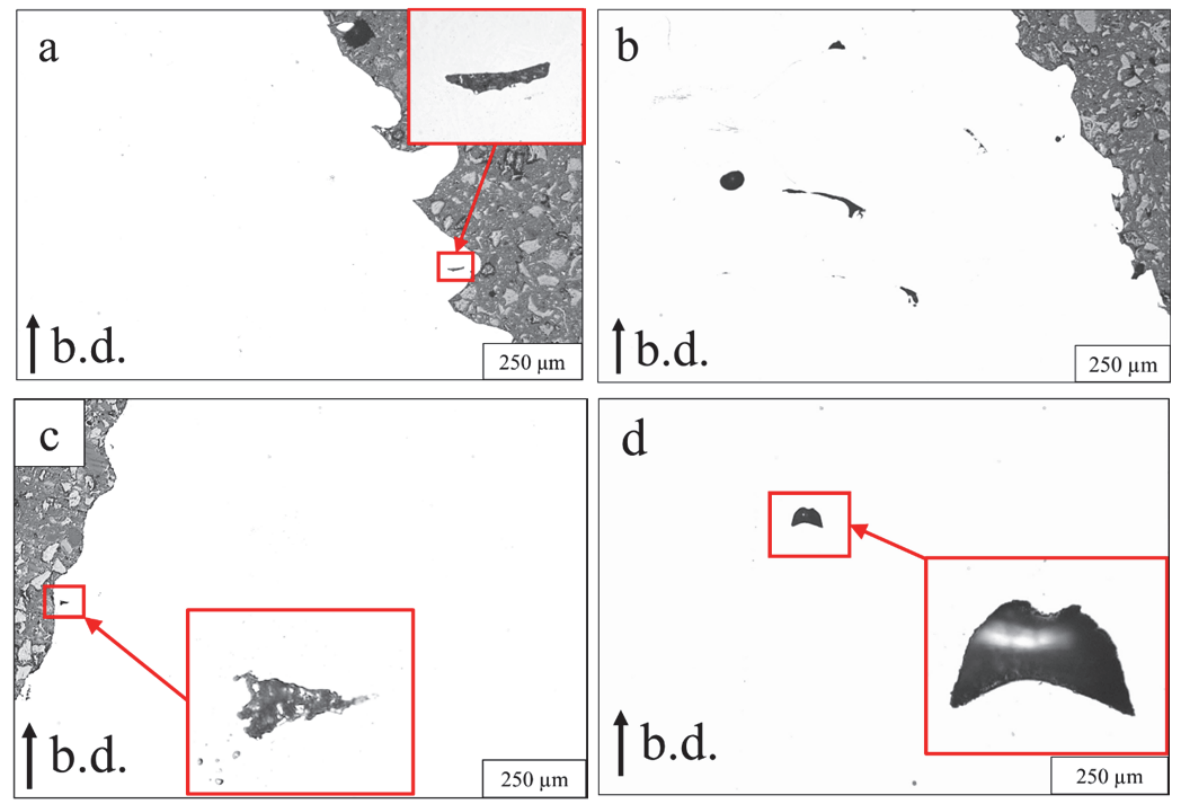

Figure 11. a.) EBM with Hot Isostatic Pressing (HIP), b.) EBM without HIP, c.) LS with HIP, d.) LS without HIP, b.d.=Building direction 


\section{MATERIALS AND EXPERIMENTAL METHODS}

\subsection{Material}

Additive manufactured Ti6Al4V samples were manufactured using both LS and EBM processes. All AM samples that were investigated in the papers included in this thesis were manufactured in one single LS build and one EBM build to avoid batch-to-batch variations. An EOS M 290 equipment was used for LS with 30 $\mu \mathrm{m}$ build layers and an average sized powder of $50 \mu \mathrm{m}$. Furthermore, an Arcam A2 equipment was used for EBM with a powder size range of $45-100 \mu \mathrm{m}$ and $50 \mu \mathrm{m}$ build layers. A wrought $\varnothing 30 \mathrm{~mm}$ Ti6Al4V bar, in mill annealed condition, was used for reference tests.

\subsubsection{Post Processing}

The LS samples were stress relieved (SR) to reduce residual stresses inherent from the process by heat treatment in argon gas at $650^{\circ} \mathrm{C}$ for $3 \mathrm{~h}$. Sandblasting were used to remove loosely bound powder grains from the surface of the LS samples while blasting with titanium powder were used for the EBM samples. To reduce internal porosity, Hot Isostatic Pressing (HIP) heat treatment was performed for the AM samples in an argon gas environment at $920^{\circ} \mathrm{C}$ and $1000 \mathrm{bar}$ pressure for $2 \mathrm{~h}$. Five (5) fatigue test series were excluded from the HIP treatment to be used as references, see Table 5 .

\subsubsection{Fatigue Test Specimens}

The AM fatigue specimens were manufactured with the loading direction in the vertical build direction, the Z-direction, since this orientation generates both the roughest as-built surface [2] and LOF defects oriented perpendicular to the load direction [29]. The fatigue test series are summarized in Table 5.

Two (2) types of fatigue specimen geometries were used, as illustrated in Figure 12 and Figure 13. One (type 1) with an un-notched surface and a theoretical stress concentration factor $\left(\mathrm{K}_{\mathrm{t}}\right)$ of 1 and one (type 2 ) with a notch with a radius of $0.85 \mathrm{~mm}$ and a stress concentration factor of $\mathrm{K}_{\mathrm{t}}=2.5$. The LS and EBM specimens were produced with two surface conditions; rough as-built AM surface and machined-and-polished. In this thesis, the rough AM produced surface is referred to as rough as-built surface even though blasting and heat treatment were performed as post processes. 
Table 5. Overview of the investigated fatigue test series for Ti6Al4V. HIP=Hot Isostatic Pressing, $\mathrm{SR}=$ Stress relieving.

\begin{tabular}{|l|l|l|l|l|}
\hline Material & $\begin{array}{l}\text { Heat treat- } \\
\text { ment }\end{array}$ & Surface & $\begin{array}{l}\text { Constant } \\
\text { amplitude } \\
\text { testing }\end{array}$ & $\begin{array}{l}\text { Variable } \\
\text { amplitude } \\
\text { testing }\end{array}$ \\
\hline EBM & HIP & $\begin{array}{l}\text { Specimen } \\
\text { type }\end{array}$ & $\begin{array}{l}\text { Specimen } \\
\text { type }\end{array}$ \\
\hline EBM & HIP & Rolished & - & - \\
\hline EBM & none & Rough as-built & $1 \& 2$ & $1 \& 2$ \\
\hline LS & SR+HIP & $\begin{array}{l}\text { Machined-and- } \\
\text { polished }\end{array}$ & $1 \& 2$ & $1 \& 2$ \\
\hline LS & SR+HIP & Rough as-built & $1 \& 2$ & - \\
\hline LS & SR & Rough as-built & 1 & $1 \& 2$ \\
\hline $\begin{array}{l}\text { Wrought } \\
\text { bar }\end{array}$ & Mill annealed & $\begin{array}{l}\text { Machined-and- } \\
\text { polished }\end{array}$ & $1 \& 2$ & $1 \& 2$ \\
\hline
\end{tabular}
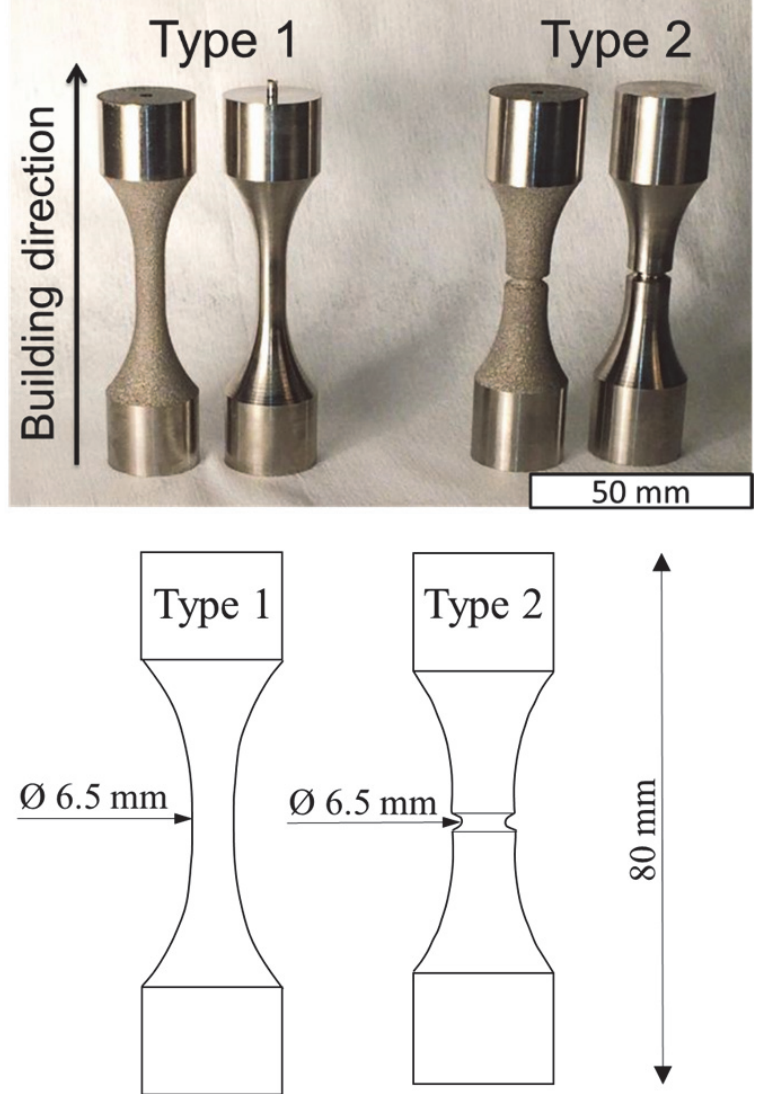

Figure 12. Fatigue specimens with rough as-build surfaces and machined surfaces. Images from paper II. 

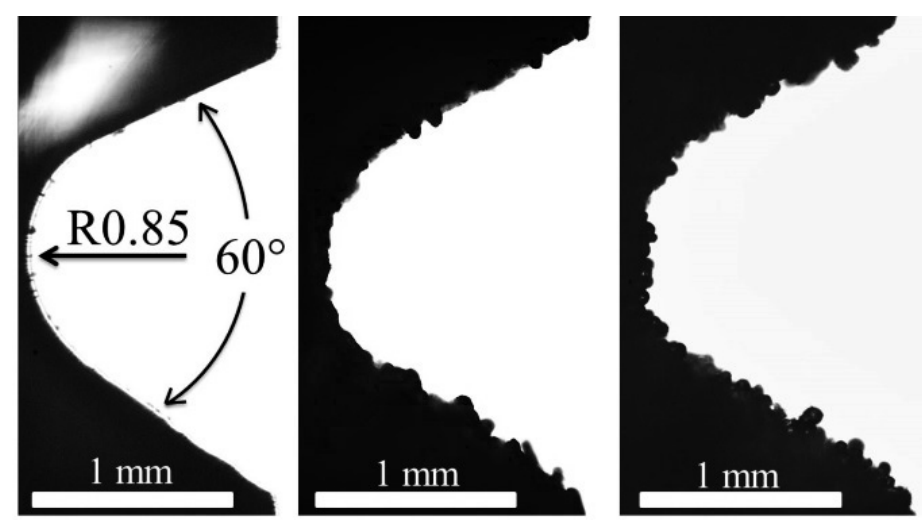

Figure 13. Type 2 specimen notch with stress concentration $K_{t}=2.5$. Machined notch (left), LS-built notch (middle) and EBM-built notch (right). Images from paper I.

\subsection{Testing}

\subsubsection{Hardness Testing}

Vickers hardness (HV5) was tested with a Struers Durascan hardness test equipment. The minimum distance between both individual indents and to the outer edge fulfils the requirements in ASTM E384.

\subsubsection{Surface Roughness}

The surface roughness of cut-out samples was studies using a Nikon Optishot optical microscope and further evaluated with image analysing technique. The surface roughness over an evaluation length of $15 \mathrm{~mm}$ was image analysed with an in-house Matlab script [32] that acquires the combined surface roughness profile for multiple micrographs. The surface roughness parameters, $\mathrm{R}_{\mathrm{a}}$ (arithmetical mean deviation within a sampling length) and $R_{v}$ (maximum profile valley depth within a sampling length) are thereafter calculated from the roughness profile.

\subsubsection{Internal Defect Investigation}

A Nikon Optishot optical microscope was used to investigate the presence of internal defects of polished cut-out AM samples.

\subsubsection{Tensile Testing}

Tensile testing was performed at room temperature in a servo hydraulic test rig with an Instron 8800 control system. A loading rate corresponding to 0.006 $\mathrm{mm} / \mathrm{mm} / \mathrm{min}$ was applied up to the yield strength and thereafter 0.043 $\mathrm{mm} / \mathrm{mm} / \mathrm{min}$ until fracture. 


\subsubsection{Constant Load Amplitude Testing}

Fatigue testing with constant amplitude loading was performed in a servo hydraulic fatigue test rig with an Instron 8800 controller and an Instron $\pm 50 \mathrm{kN}$ load cell. All constant amplitude tests, in this study, were performed at room temperature with a load frequency of $20 \mathrm{~Hz}$ and a stress ratio of $\mathrm{R}=0.1$. The fracture surfaces were investigated by stereomicroscopy and representative fracture surfaces from each test series were further analysed by a HITACHI SU-70 field emission Scanning Electron Microscope (SEM) operating at $15 \mathrm{kV}$.

\subsubsection{Aircraft Spectrum for Fatigue Loading}

The fighter aircraft wing bending spectrum FALSTAFF (Fighter Aircraft Loading STAndard For Fatigue) [33] was used for both cumulative damage calculations and variable amplitude fatigue testing. Short-FALSTAFF, developed by CEAT in Toulouse [34], which is a modified version of the standard FALSTAFF was used to decrease the test times. Compared to the standard FALSTAFF, the Short-FALSTAFF, illustrated in Figure 14, has about 50\% less cycles but the remaining cycles still contribute to almost all of the cumulative damage achieved with the standard FALSTAFF sequence [35]. One Short-FALSTAFF sequence correspond to 200 simulated flights and consists of 9006 rain-flow counted cycles.

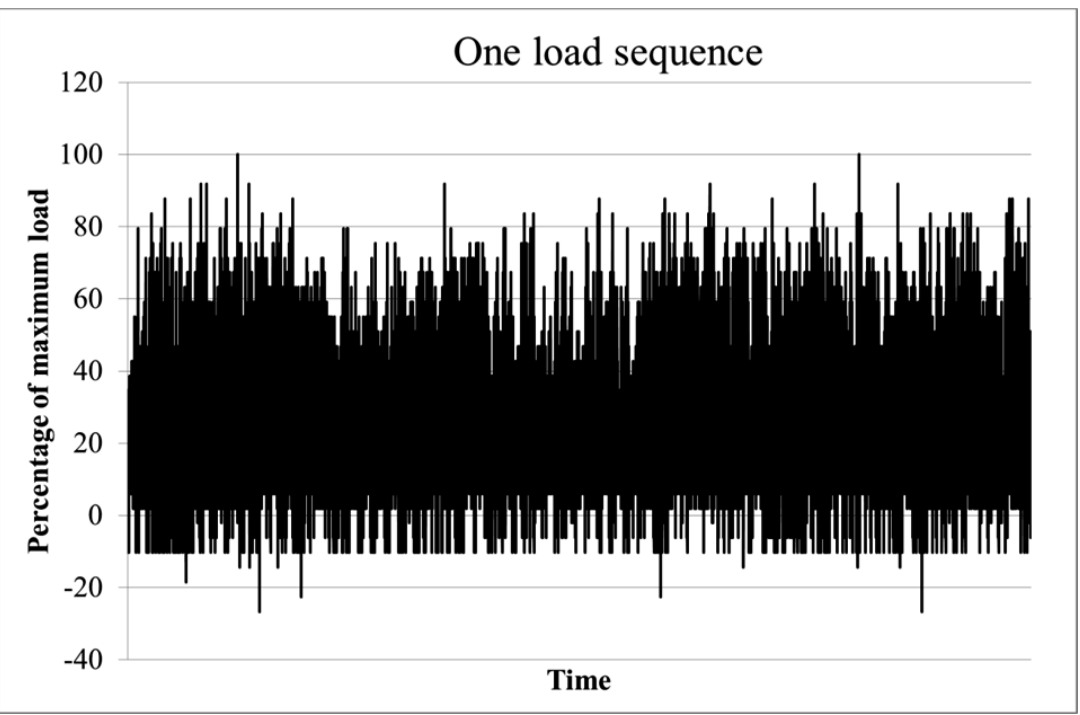

Figure 14. One Short-FALSTAFF load sequence in which the maximum tensile peak (100) correspond to the maximum net section peak stress used in the experimental tests. Graph from paper II. 


\subsubsection{Constant Amplitude Fatigue Design Data}

In general, the fatigue life of variable amplitude loaded structures are calculated using constant amplitude fatigue data and a cumulative damage approach with, for example, Palmgren-Miner's rule [36], presented in Eq. 1 [37,38]. The constant amplitude fatigue results, presented in this thesis, were manually curvefitted to produce Wöhler curves. Moreover, Wöhler curves for Ti6Al4V castings, from the Saab Aeronautics company material database, were scaled to fit these new curve-fitted Wöhler curves with a stress amplitude $\left(\sigma_{\mathrm{a}}\right)$ linear adjustment function which is schematically presented in Figure 15.

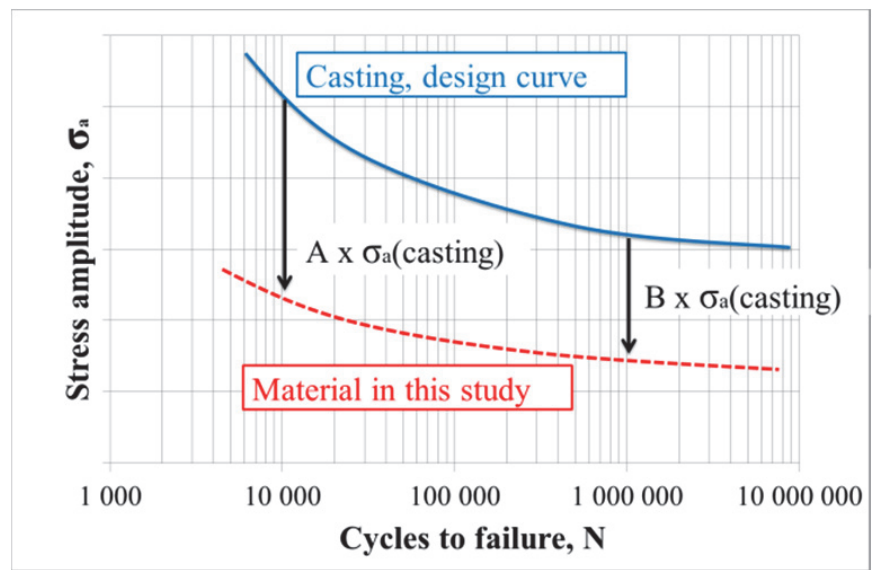

Figure 15. A schematic illustration of the linear adjustment procedure. A and B are constants. Graph from paper II.

The same adjustment function was then further applied to the complete Haigh diagram for Ti6Al4V casting, from the Saab Aeronautics company material database, in order to derive a Haigh diagram for each of the constant amplitude test series presented in this thesis.

\subsubsection{Cumulative Damage Approach for Fatigue Life Prediction}

The rain-flow counted cycles in the Short-FALSTAFF load sequence and the derived Haigh diagram, for each fatigue test series, were used for cumulative damage calculations according to Palmgren-Miner rule [37,38], see Eq. 1, in which $\mathrm{D}$ is the cumulative damage, $\mathrm{n}_{\mathrm{i}}$ is the numbers of applied load cycles of type $\mathrm{i}$ and $\mathrm{N}_{\mathrm{i}}$ is the number of type $\mathrm{i}$ cycles that equals fatigue failure.

$$
D=\sum_{i=1}^{k} \frac{n_{i}}{N_{i}}
$$

A schematic distribution of the rain-flow counted cycles in one ShortFALSTAFF load sequence is illustrated in a Haigh diagram format in Figure 16. 
The amount of cycles to fatigue failure for each data point in Figure 16 is calculated for constant mean stress $\left(\sigma_{\mathrm{m}}\right)$ for $\mathrm{R}<-1$, for constant minimum stress $\left(\sigma_{\min }\right)$ for $\mathrm{R}>0$ and by interpolation of amplitude stress $\left(\sigma_{\mathrm{a}}\right)$ between different R-values when $-1 \leq \mathrm{R} \leq 0$ using extracted Wöhler curves in the derived Haigh diagram.

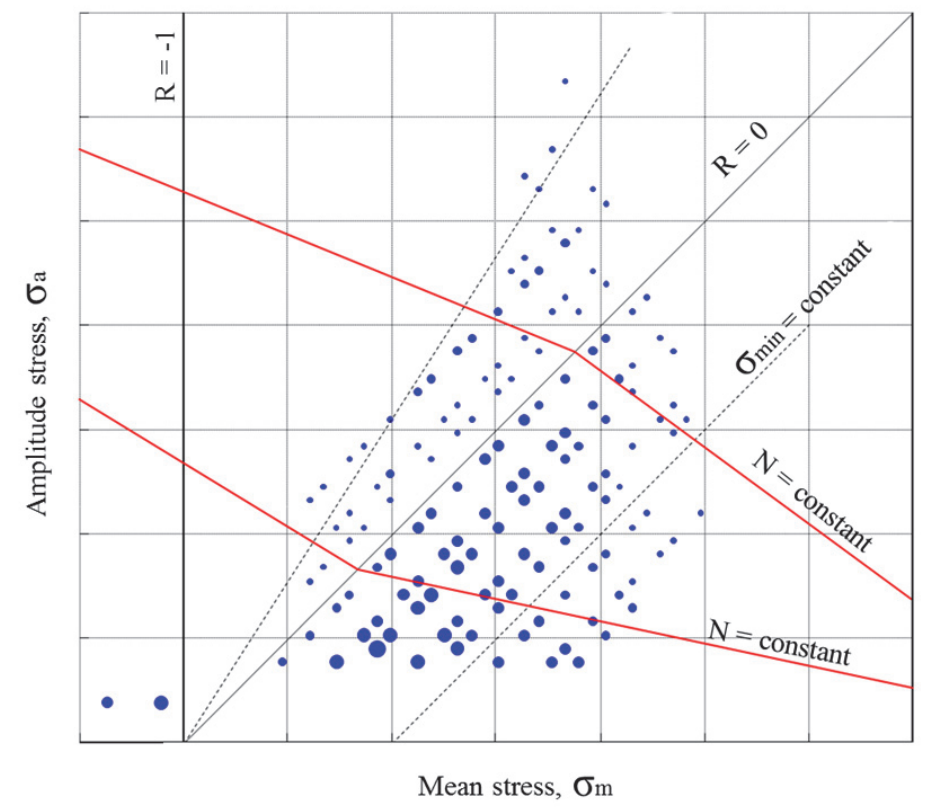

Figure 16. A schematic Haigh diagram for one Short-FALSTAFF load sequence. Larger data points represent a greater number of that rain-flow counted cycle in the load sequence. Graph from paper II.

\subsubsection{Variable Load Amplitude Testing}

Variable amplitude fatigue testing was performed at the maximum net section peak stress that was calculated by cumulative damage approach to give 15000 simulated flights. The testing was performed at $10 \mathrm{~Hz}$ at room temperature using a servo hydraulic fatigue test rig, an Instron 8800 control system and an Instron $\pm 50 \mathrm{kN}$ load cell. For each test series, the Short-FALSTAFF load sequence was scaled to correspond to the maximum net section peak stress that was predicted to give 15000 simulated flights. The load sequence was applied over and over again until the test specimen failed by fracture or runout. The fracture surfaces were investigated by stereomicroscopy and further analysed by a HITACHI SU70 field emission scanning electron microscope (SEM) operating at $15 \mathrm{kV}$. 


\section{STATIC STRENGTH}

Static tensile strength for AM Ti6Al4V has previously been widely studied and average values of tensile properties are presented in Table 6 . The tensile strength for AM material with machined surfaces is in the same range as the strength of wrought material even though there are variations between material from different AM equipment, batch-to-batch variations and variations between different material orientations in the build chamber [2]. AM Ti6Al4V has, however, generally lower ductility compared to wrought material [2]. The tensile fracture mode is mainly intergranular along $\alpha$-grain boundaries or columnar prior $\beta$-grain boundaries which are aligned in the vertical build direction [28]. This results in a rougher fracture surface for specimens loaded in the vertical direction since the cracks cannot follow the columnar grain boundaries in contrast to horizontal loaded specimens [28].

The microstructure of AM Ti6Al4V is coarsened during post heat treatments and it has previously been reported that HIP treatment reduces the static strength and increase the ductility of the material [22]. This behaviour was confirmed in the present study, both by Vickers hardness and tensile testing which is illustrated in Figure 17. The reduction of strength and hardness for material subjected to HIP is considerably larger for LS material compared to EBM material. This can, at least partly, be attributed to the EBM material already having a coarsened microstructure inherent from the hot manufacturing process.

Thin walled AM material with rough as-built surface has reduced static strength compared to bulk material [24]. This is behaviour can most likely be attributed to the surface morphology in which the rough as-built surface is a large part of the thin wall cross section and the load bearing area is thereby considerably reduced. This reducing effect can be neglected for thicker wall thicknesses, above $4 \mathrm{~mm}$, and for AM material with machined surfaces [24].

Hardness testing performed in multiple positions, at a given interval between the edge and the centre of the samples, showed no hardness variation across the thickness profile which is illustrated by Figure 17. 
Table 6. Tensile strength of AM Ti6A14V with machined surfaces (average values). $\mathrm{HIP}=$ Hot Isostatic Pressing at $915-920^{\circ} \mathrm{C}$ for $2 \mathrm{~h}$ at $1000 \mathrm{bar}, \mathrm{SR}=$ stress reliving at $650-700^{\circ} \mathrm{C}$ for $1-3 \mathrm{~h}, \mathrm{Z}$ - vertical direction, $\mathrm{X}=$ horizontal direction, $\mathrm{L}=$ =longitudinal

\begin{tabular}{|c|c|c|c|c|c|}
\hline Material & $\begin{array}{l}\text { Load } \\
\text { direc- } \\
\text { tion }\end{array}$ & $\begin{array}{l}\text { Ultimate } \\
\text { tensile } \\
\text { strength, } \\
\text { MPa }\end{array}$ & $\begin{array}{l}\text { Ultimate } \\
\text { tensile } \\
\text { strength, } \\
\text { MPa }\end{array}$ & $\begin{array}{l}\text { Elongation } \\
\text { to fracture, } \\
\%\end{array}$ & $\begin{array}{l}\text { Elongation } \\
\text { to fracture, } \\
\%\end{array}$ \\
\hline no HIP / HIP & & no HIP & HIP & no HIP & HIP \\
\hline $\begin{array}{l}\text { EBM } \\
\text { This study }\end{array}$ & $\mathrm{Z}$ & 1065 & 1005 & 12 & 16 \\
\hline \multirow{2}{*}{$\begin{array}{l}\text { EBM }[26,39] \\
{[26]}\end{array}$} & Z & 935 & 905 & 14 & 14 \\
\hline & $X$ & 970 & 960 & 12 & 14 \\
\hline $\begin{array}{l}\text { LS } \\
\text { This study }\end{array}$ & $\mathrm{Z}$ & $\mathrm{N} / \mathrm{A}$ & 970 & N/A & 14 \\
\hline $\begin{array}{l}\operatorname{LS}[40,41] \\
{[21,27]}\end{array}$ & Z & $\begin{array}{l}1200 \\
1135 \text { (SR) }\end{array}$ & 1020 & $\begin{array}{l}3 \\
9 \text { (SR) }\end{array}$ & 15 \\
\hline LS [27] & $\mathrm{X}$ & 1185 (SR) & $\mathrm{N} / \mathrm{A}$ & 7 (SR) & $\mathrm{N} / \mathrm{A}$ \\
\hline $\begin{array}{l}\text { Wrought, } \\
\text { annealed. } \\
\text { This study }\end{array}$ & $\mathrm{L}$ & 1000 & N/A & 17 & N/A \\
\hline $\begin{array}{l}\text { Wrought, } \\
\text { annealed }[21,39]\end{array}$ & N/A & 930 & N/A & 19 & N/A \\
\hline
\end{tabular}

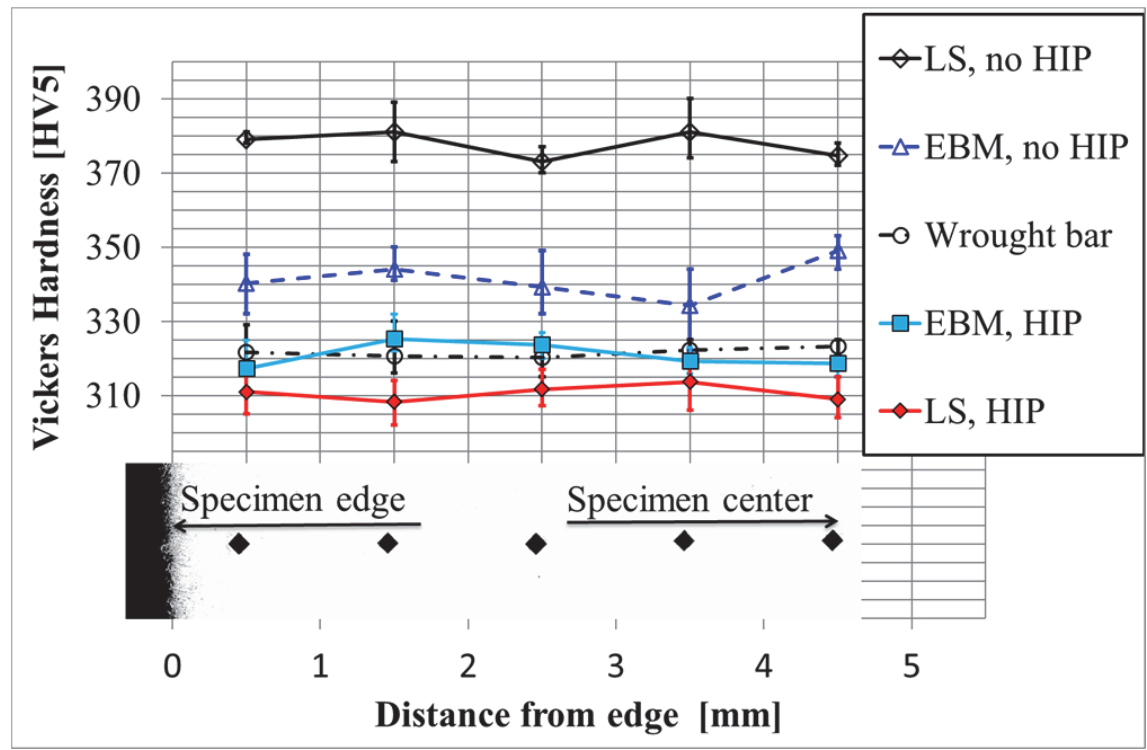

Figure 17. Mean hardness for different material conditions of Ti6Al4V, ranging from specimen edge to centre. The error bar indicates the maximum and minimum hardness measurement for each position. Three tests per position. Graph from paper I. 


\section{SURFACE ROUGHNESS}

The raw as-built surface of AM material can be very rough and depends both on process parameters and part geometry. Materials manufactured with EBM have about twice the surface roughness compared to LS materials, as illustrated in Figure 18 and Table 7, which can be attributed to the thicker build layers, larger powder sizes and higher scan speeds of the EBM process [13]. The surface roughness $R_{a}$ (arithmetical mean deviation) has been found to be in the same range as the individual layer thickness of each build [12], see Table 7. Furthermore, the part geometry and the orientation of part in the build chamber have a large impact on the roughness [2]. The surface roughness of a surface parallel to the vertical build direction, $Z$, can be 2-3 times rougher than a flat horizontal surface [2] and the surface roughness can be attributed to several mechanisms including stair stepping and partially melted powder grains on the surface [42].
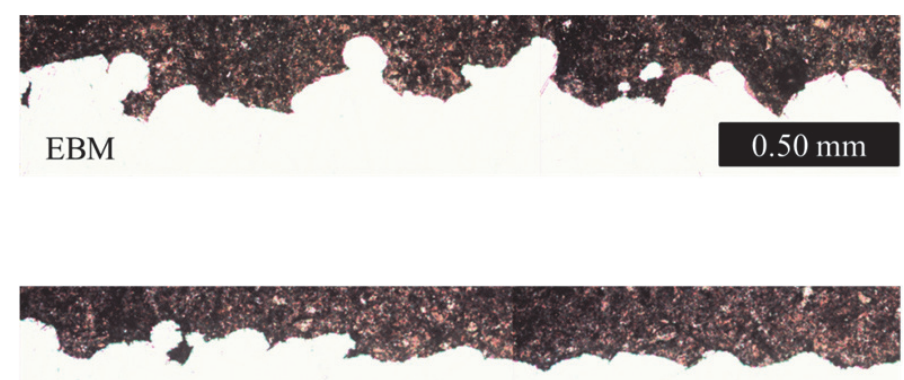

LS

$0.50 \mathrm{~mm}$

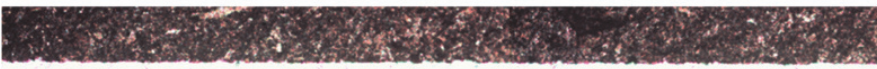

Machined-and-polished

$0.50 \mathrm{~mm}$

Figure 18. As-built AM surfaces compared to machined-and-polished surface. The AM surfaces were post processed with light blasting to remove loosely bound powder grains. Images from paper I. 
Table 7. Average surface roughness for EBM and LS Ti6Al4V. $\mathrm{R}_{\mathrm{a}}=$ arithmetical mean deviation within a sampling length, $\mathrm{AB}=$ as built surface, $\mathrm{m} \& \mathrm{p}=$ machined-and-polished surface

\begin{tabular}{|l|l|l|l|}
\hline Surface & $\begin{array}{l}\text { Surface } \\
\text { orientation }\end{array}$ & $\begin{array}{l}\text { Layer thickness } \\
(\boldsymbol{\mu m})\end{array}$ & $\begin{array}{l}\text { Surface roughness } \\
\mathbf{R}_{\mathbf{a}}(\boldsymbol{\mu \mathbf { m }})\end{array}$ \\
\hline m\&p, this study & & & 2 \\
\hline EBM AB, this study & $\mathrm{Z}$ & 50 & 34 \\
\hline EBM, [12,43] & $\mathrm{Z}$ & 100 & 114 \\
\hline EBM, [44] & $\mathrm{Z}$ & 50 & 26 \\
\hline LS, this study & $\mathrm{Z}$ & 30 & 14 \\
\hline LS, [12,15,28] & $\mathrm{Z}$ & $40-50$ & 36 \\
\hline
\end{tabular}

The topography of rough as-built AM surfaces consists of partially melted powder grains which form sharp radii of curvature as illustrated in Figure 19. These radii act as micro notches which give rise to local stress concentrations which can be detrimental for fatigue life $[12,42]$.

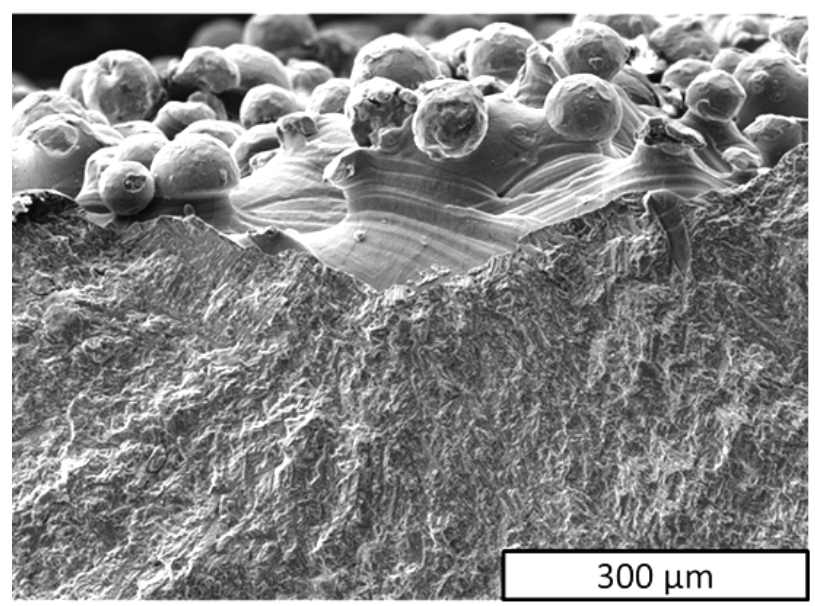

Figure 19. Micro notch formed at the surface of an EBM sample. A fatigue crack initiation is visible at the root of the notch. Image from paper I.

In a previous study, Chan et al. [12] compared the rough as-built surfaces of both EBM and LS Ti6Al4V and found that EBM surfaces consist of peaks and valleys, in which the valleys are incompletely filled layers while LS surfaces have completely filled layers. Moreover, Chan et al. calculated the local stress concentrations factor, $\mathrm{K}_{\mathrm{t}}$, for the rough as-built AM surfaces at typical crack initiations locations using the surface roughness, $\mathrm{R}_{\mathrm{v}}$, as notch depth and the radii of curvature at the crack initiation position. The EBM surface corresponded to $\mathrm{K}_{\mathrm{t}}=9.1$ and the LS surface to $\mathrm{K}_{\mathrm{t}}=5.4$ which both are major stress concentrations factors. 
Surface roughness can be measured with different equipment in which one of the most common is the stylus profilometer. However, the rough as-built surface of AM materials contains narrow valleys and overhangs which can be difficult to reach with the stylus profilometer tip. Therefore, the surface roughness measured with a profilometer could be underestimated if the stylus cannot follow the AM peaks and valleys correctly [44]. The surface roughness investigated in this study were therefore measured with image analysing of micrographs. 


\section{FATIGUE}

The fatigue properties of AM material are dependent on both AM method and post process procedures and the fatigue life can be reduced due to, for example, the rough AM as-built surface, geometrical notches or material defects inside the material. All these features lead to an increased local stress concentration which promotes fatigue crack initiation. Moreover, the fatigue behaviour of AM materials with rough as-built surfaces is dominated by the surface roughness rather than by internal defects [18].

The constant amplitude fatigue behaviour of AM Ti6Al4V has been investigated in the present study both for samples with machined surface and samples with rough as-built surface. The fatigue limit is compared, in Table 8 , to several previous studies for different material conditions showing a large spread in strength which further enlighten the fact that there can be a large variation in material quality for AM materials even though the same type of AM equipment is used.

Table 8. Fatigue limit at $5 \times 10^{6}$ cycles for AM Ti6Al4V. Un-notched (type 1) specimens tested with constant amplitude loading at stress ratio $\mathrm{R}=0.1$.

\begin{tabular}{|l|l|ll|}
\hline Material/condition & This study & Previous studies & \\
\hline EBM, HIP, m\&p surface & $800 \mathrm{MPa}(\mathrm{Z})$ & $\begin{array}{l}550-600 \mathrm{MPa}(\mathrm{Z}) \\
570-650 \mathrm{MPa}(\mathrm{X})\end{array}$ & {$[26,46]$} \\
& & {$[22,26]$} \\
\hline LS, SR, HIP, m\&p surface & $500-600$ & $650 \mathrm{MPa}(\mathrm{X})$ & {$[22]$} \\
& $\mathrm{MPa}(\mathrm{Z})$ & & \\
\hline EBM, HIP, AB surface & $200 \mathrm{MPa}(\mathrm{Z})$ & $140 \mathrm{MPa}(\mathrm{X})$ & {$[22]$} \\
\hline LS, SR, HIP, AB surface & $300 \mathrm{MPa}(\mathrm{Z})$ & $185 \mathrm{MPa}(\mathrm{X})$ & {$[22]$} \\
\hline EBM, AB surface & $180 \mathrm{MPa}(\mathrm{Z})$ & $200-250(\mathrm{Z})$ & {$[46]$} \\
& & $150(\mathrm{X})$ & {$[22]$} \\
\hline LS, SR, AB surface & $300 \mathrm{MPa}(\mathrm{Z})$ & $200-450 \mathrm{MPa}(\mathrm{Z})$ & {$[47-48]$} \\
& & $200 \mathrm{MPa}(\mathrm{X})$ & {$[22]$} \\
\hline
\end{tabular}

$\mathrm{HIP}=$ Hot isostatic pressing, $\mathrm{m} \& \mathrm{p}=$ machined-and-polished, $\mathrm{SR}=$ stress relieved, $\mathrm{AB}=$ as-built surface, $\mathrm{Z}=$ loading in vertical direction (building direction), $\mathrm{X}=$ loading in horizontal direction. 


\subsection{Effect of Surface Roughness}

The as-built AM surface is generally very rough and the roughness depends both on the AM process and the surface orientation in the built chamber. Fatigue specimens with rough as-built surfaces generally have fatigue failure starting from the rough surface $[11,23,47,48]$, see Figure 19, and results from the present study show that there is a distinct trend that a rougher surface contribute to a reduced fatigue limit as illustrated by Figure 20. For machined AM surfaces, however, fatigue cracks can either start from internal features or from the surface, at internal features that is located at the after machining [11,21], see Figure 21.

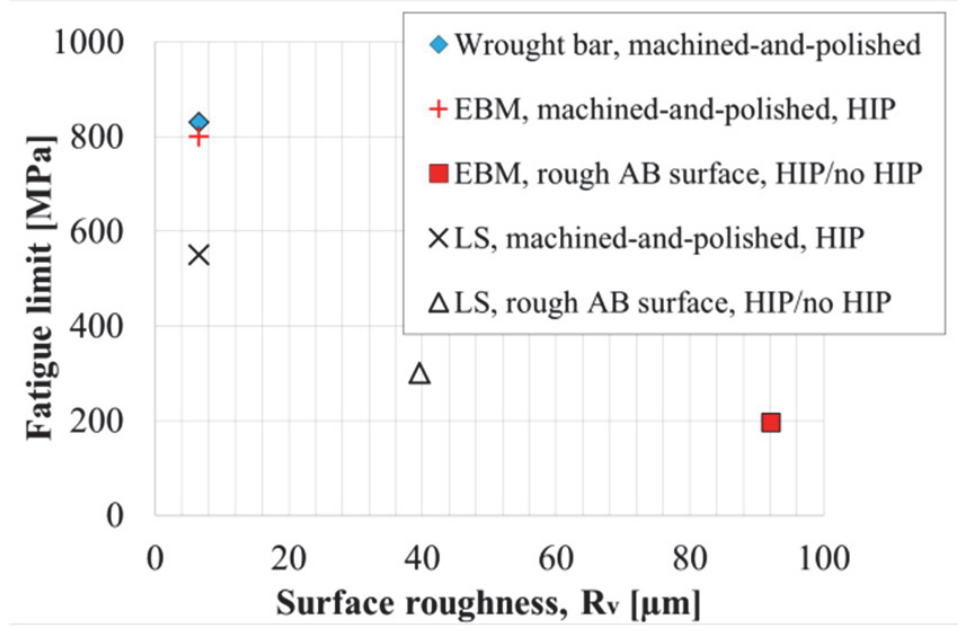

Figure 20. Fatigue limit (at $5 \times 10^{6}$ cycles) in comparison to surfaces roughness. $R_{v}=$ maximum profile valley depth, $\mathrm{AB}=$ as-built surface., $\mathrm{HIP}=$ Hot Isostatic Pressing. Graph from paper I.
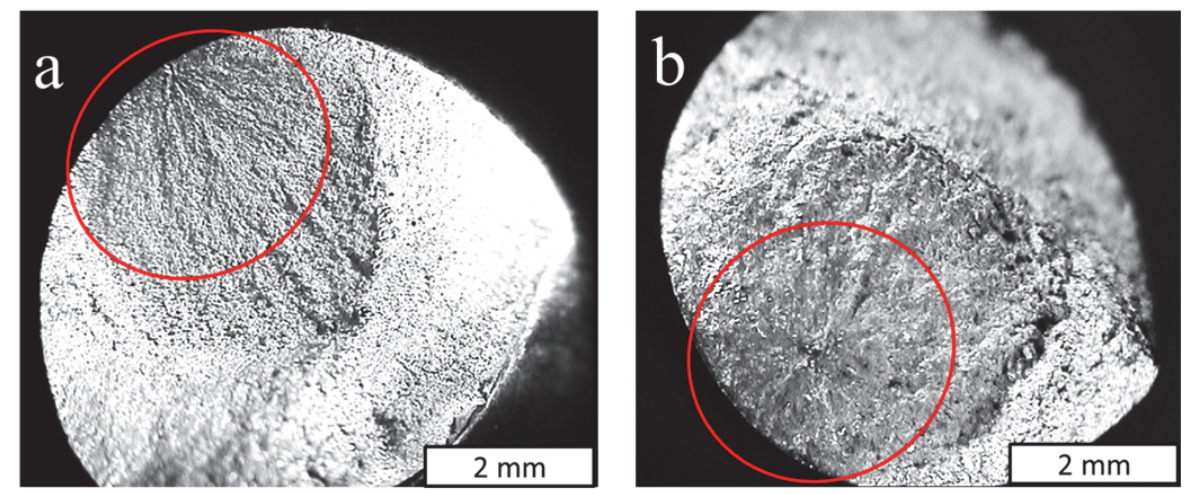

Figure 21. Fracture surfaces with crack initiations location marked with a red circle. a.) EBM+HIP sample with machined-and-polished surface with crack initiation at the surface, b.) LS+HIP sample with machined-and-polished surface with crack initiation at an internal feature. $\mathrm{HIP}=$ Hot Isostatic Pressing. Images from paper I. 


\subsection{Effect of Hot Isostatic Pressing}

In literature, it is often stated that Hot Isostatic Pressing (HIP) improves the fatigue properties of AM materials by eliminating internal pores and voids, see Figure 11. This statement is based on fatigue tests with machined-and-polished specimens in which several previous investigations show similar fatigue life for HIP:ed LS [21,40] and EBM [26] Ti6Al4V material compared to conventional wrought material. However, results from the present study show that HIP has negligible enhancing effect on fatigue strength for EBM and LS materials with rough as-built surfaces, see Figure 22 and Figure 23. These findings apply both for un-notched (type 1 samples with $\mathrm{K}_{\mathrm{t}}=1$ ) geometries but also for geometrical notches with as-built surface (type 2 sample with $\mathrm{K}_{\mathrm{t}}=2.5$ ) built directly by AM. These findings are confirmed by a recent study by Greitemeier et al. [22] in which un-notched samples with rough as-built surfaces were studied. Consequently, the same fatigue design data, for fatigue analysis, can be used for either HIP:ed or non-HIP:ed AM materials.

Even though negligible for fatigue design data, the fatigue results for the unnotches EBM specimens (type 1), presented in Figure 22, show a minor tendency of lower fatigue limit for specimens without HIP. This could be explained by the presence of multiple Lack-of-Fusion (LOF) defects in the EBM samples, see Figure 24, and even though the cracks start from the rough surface these LOF will reduce the load bearing area of the fatigue specimen and thereby reduce the apparent fatigue strength. Rough measurements show that approximate 5\% of the fatigue fracture area for EBM specimens without HIP was covered by LOF defects. If the maximum stress, for the un-notches EBM specimens (type 1) without HIP, is re-calculated with 5\% smaller cross section area, the test results for the un-HIP:ed material will be in line with the HIP:ed material. This shows that, even though the fatigue properties of AM material with rough as-built surfaces is dominated by the surface roughness, a large amount of internal defects can still have a minor influence on the fatigue strength. 


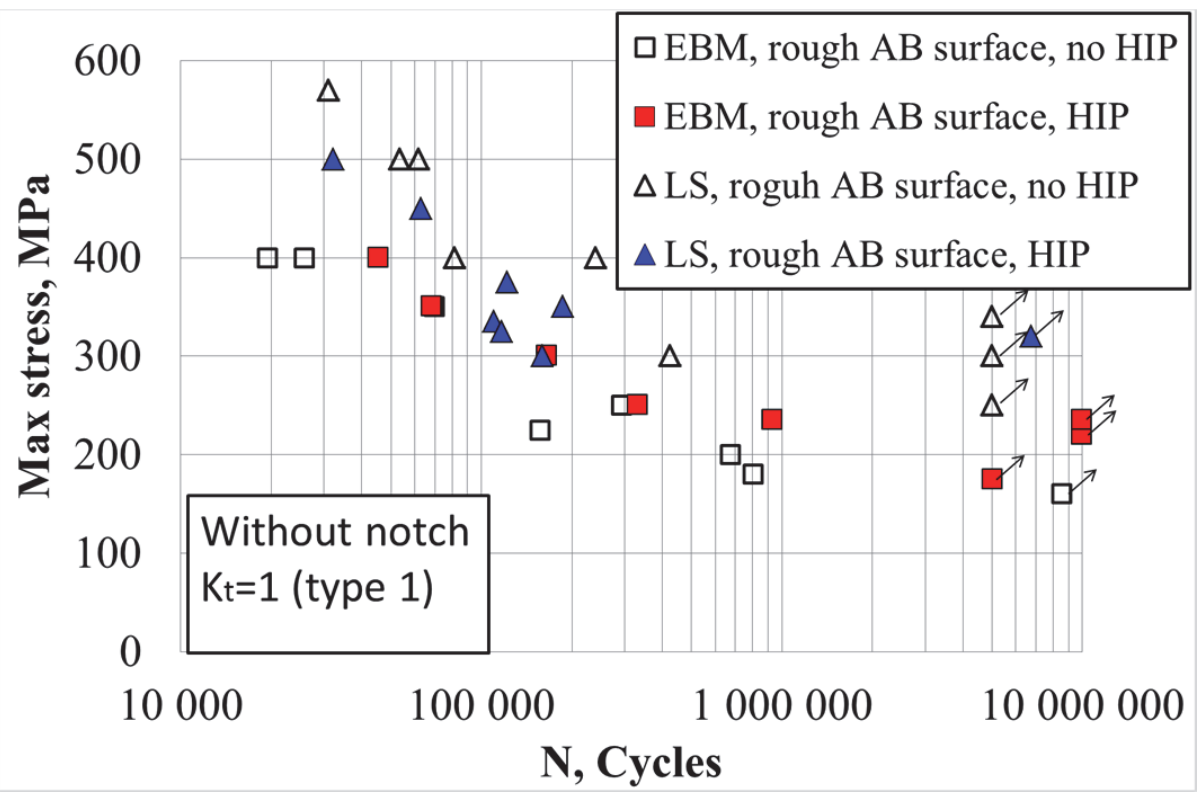

Figure 22. Fatigue life for AM samples with and without HIP treatment and $\mathrm{K}_{t}=1$ (type 1) geometry with rough as-built $(\mathrm{AB})$ surface. Graph from paper I.

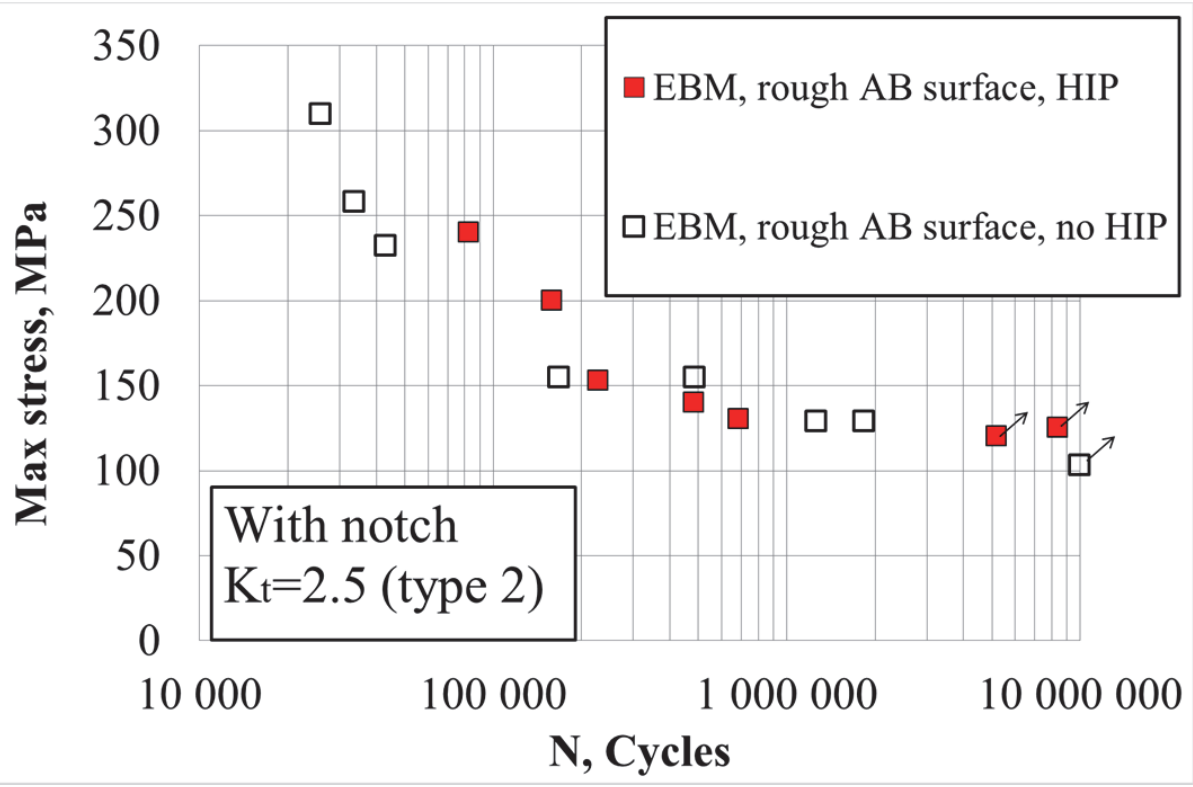

Figure 23. Fatigue life for AM samples with and without HIP treatment and $\mathrm{K}_{t}=2.5$ (type 2) geometrical notch with a rough as-built $(\mathrm{AB})$ surface. Graph from paper I. 

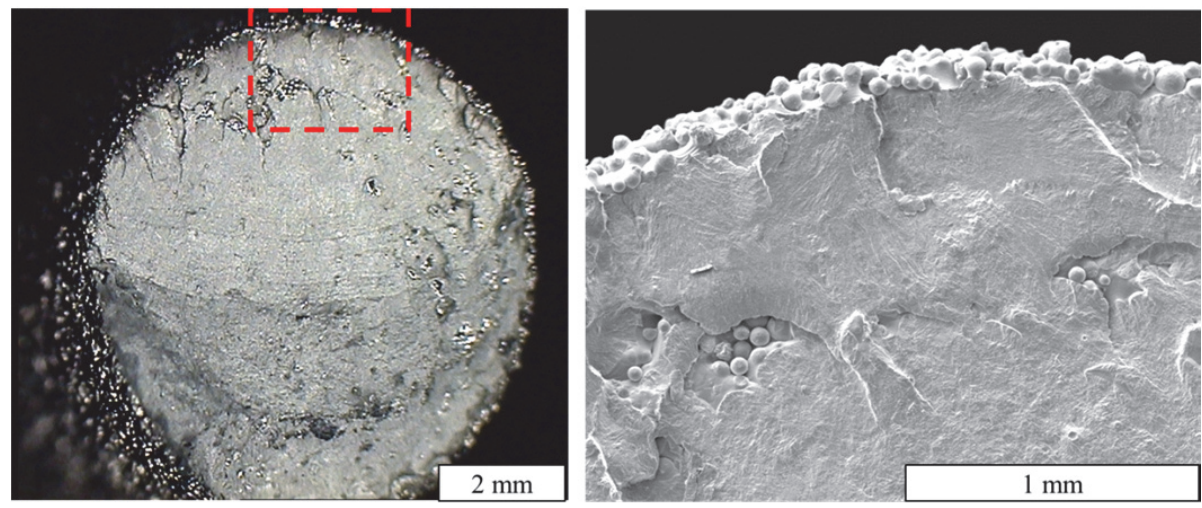

Figure 24. Fracture surface of EBM sample without HIP showing multiple lack of fusions. Images from paper II.

\subsection{Fatigue Notch Factor}

The fatigue behaviour of un-notched (type 1) Ti6Al4V specimens with rough asbuilt AM surface has been investigated in previous studies, [13,21,22,45-48]. Few aerospace parts have, however, simple flat geometries without any radii or corners that would introduce local stress concentrations. A combined effect of a rough as-built AM surface and a geometrical notch built directly by AM is therefore needed in order to predict the fatigue life for AM parts. The present study is the first study, to our knowledge, that has investigated this combined effect.

A console for the JAS 39 Gripen fighter has been re-designed, for demonstration purpose only, to an AM design to reduce the weight of the part, see Figure 25. The re-designed part has rough as-built AM surface and geometrical notches built directly by AM which both leads to increased local stress concentrations. 


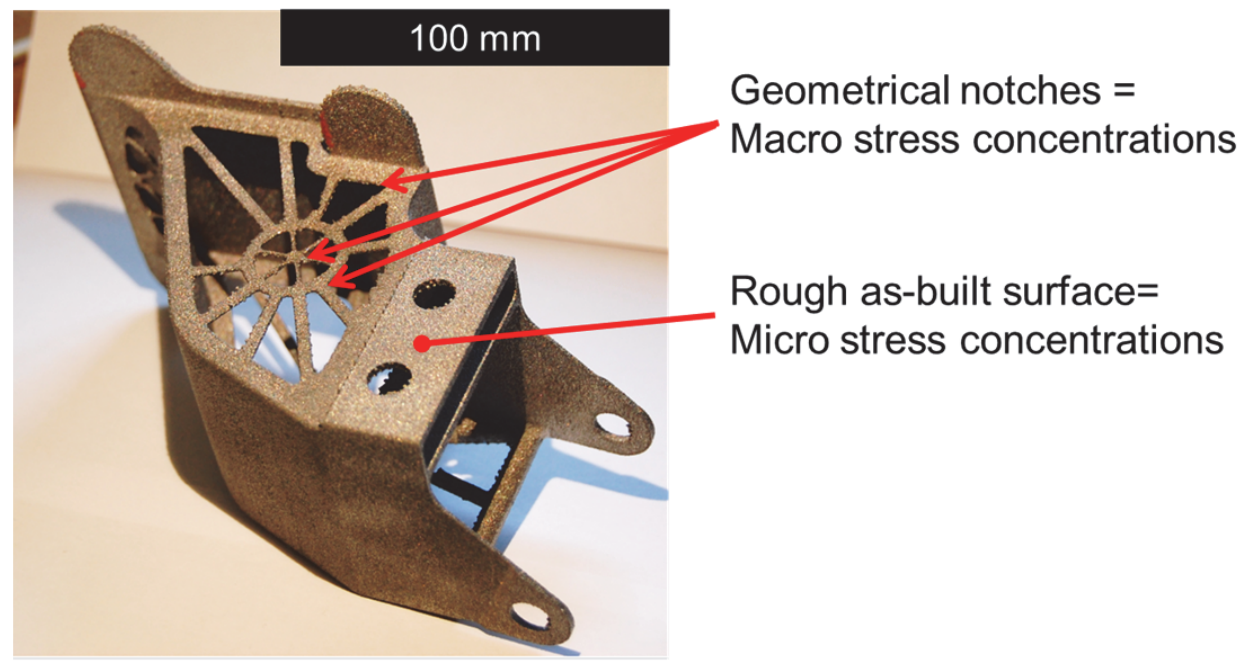

Figure 25. A console for the JAS 39 Gripen fighter, re-designed for AM for demonstration purpose.

The fatigue notch factor, $\mathrm{K}_{\mathrm{f}}$, describes the reduction of the fatigue limit due to the presence of a notch in the material, according to Eq. 1 [49].

$$
\mathrm{K}_{\mathrm{f}}=\frac{\mathrm{un}-\text { notched fatigue limit }}{\text { notched fatigue limit }}
$$

The fatigue notch factor depends on the notch-sensitivity, q, of the material and can therefore deviate from the stress concentration factor, $\mathrm{K}_{\mathrm{t}}$. In this study, both the fatigue reduction due to macro notches (geometrical notches) and due to micro notches (rough as-built AM surfaces and internal defects) have been evaluated using the fatigue notch factor. The fatigue limit for wrought bar with an unnotched $\left(\mathrm{K}_{\mathrm{t}}=1\right.$, type 1) machined-and-polished surface was used as base line and the fatigue notch factor, $\mathrm{K}_{\mathrm{f}}$, was calculated in relation to this base line for all other fatigue test series using Eq. 2. The fatigue limit was defined as the maximum stress at $5 \times 10^{6}$ cycles to failure for each test series. The resulting fatigue notch factors are presented in Table 9, Figure 26 and Figure 27 indicating the severity of different material defects in respect to the fatigue limit.

$$
\mathrm{K}_{\mathrm{f}}=\frac{\text { fatigue limit for wrought bar } \mathrm{K}_{\mathrm{t}}=1(\text { type } 1)}{\text { fatigue limit for each test series }}
$$


Table 9. Fatigue notch factor $\mathrm{K}_{\mathrm{f}}$ for both specimens with (type 2) and without (type 1) a geometrical notch. $\mathrm{HIP}=$ hot isostatic pressing, $\mathrm{AB}=$ as-built.

\begin{tabular}{|l|l|l|l|l|l|}
\hline $\begin{array}{l}\text { Fatigue } \\
\text { notch fac- } \\
\text { tor } \mathbf{K}_{\mathbf{f}}\end{array}$ & $\begin{array}{l}\text { Wrought bar, } \\
\text { machined/ } \\
\text { polished } \\
\text { surface }\end{array}$ & $\begin{array}{l}\text { EBM+HIP, } \\
\text { machined/ } \\
\text { polished } \\
\text { surface }\end{array}$ & $\begin{array}{l}\text { LS+HIP, } \\
\text { machined/ } \\
\text { polished } \\
\text { surface }\end{array}$ & $\begin{array}{l}\text { LS + } \\
\text { HIP/no HIP, } \\
\text { rough AB } \\
\text { surface }\end{array}$ & $\begin{array}{l}\text { EBM + } \\
\text { HIP/no HIP, } \\
\text { rough AB } \\
\text { surface }\end{array}$ \\
\hline $\begin{array}{l}\text { Un-notched } \\
\text { (type 1) }\end{array}$ & 1 & 1.0 & 1.5 & 2.8 & 4.3 \\
\hline $\begin{array}{l}\text { Notched } \\
\text { (type 2) }\end{array}$ & 1.61 & 1.8 & 1.8 & 6.2 & 6.6 \\
\hline
\end{tabular}

The fatigue notch factor for the notched fatigue test series (type 2 specimens) were similar when comparing EBM to LS material, for both machined and AM build notches respectively, while the un-notched test series had significant differences in fatigue notch factors.

In previous investigations by Chan [42] and Chan et al. [12] of rough as-built surfaces, both the average local stress concentration for surface micro notches, $\mathrm{K}_{\mathrm{t}}=3.3$ for EBM and $\mathrm{K}_{\mathrm{t}}=2.3$ for $\mathrm{LS}$, and the actual local stress concentration at typical crack initiation sites for un-notched specimens, $\mathrm{K}_{\mathrm{t}}=9.1$ for $\mathrm{EBM}$ and $\mathrm{K}_{\mathrm{t}}=5.4$ for LS, were determined. Consequently, there is a considerable larger difference between the maximum stress concentrations at the crack initiation compared to the average stress concentrations.

The similar fatigue notch factor, in the present study, for EBM and LS material, with machined and AM build notches respectively, can therefore most likely be attributed to a volume effect in which the crack will be guided to start at the cross section of the notch for notched samples. The probability is then low that the most severe surface or internal defect of the sample will be located at the notch and an average local stress concentration would be more likely. This will result in a similar fatigue behaviour for the notched EBM and LS samples while the unnotched samples will have failure from the most severe surface or internal defect located anywhere in gauge section of the specimen keeping the inherent differences of the EBM and LS materials. 


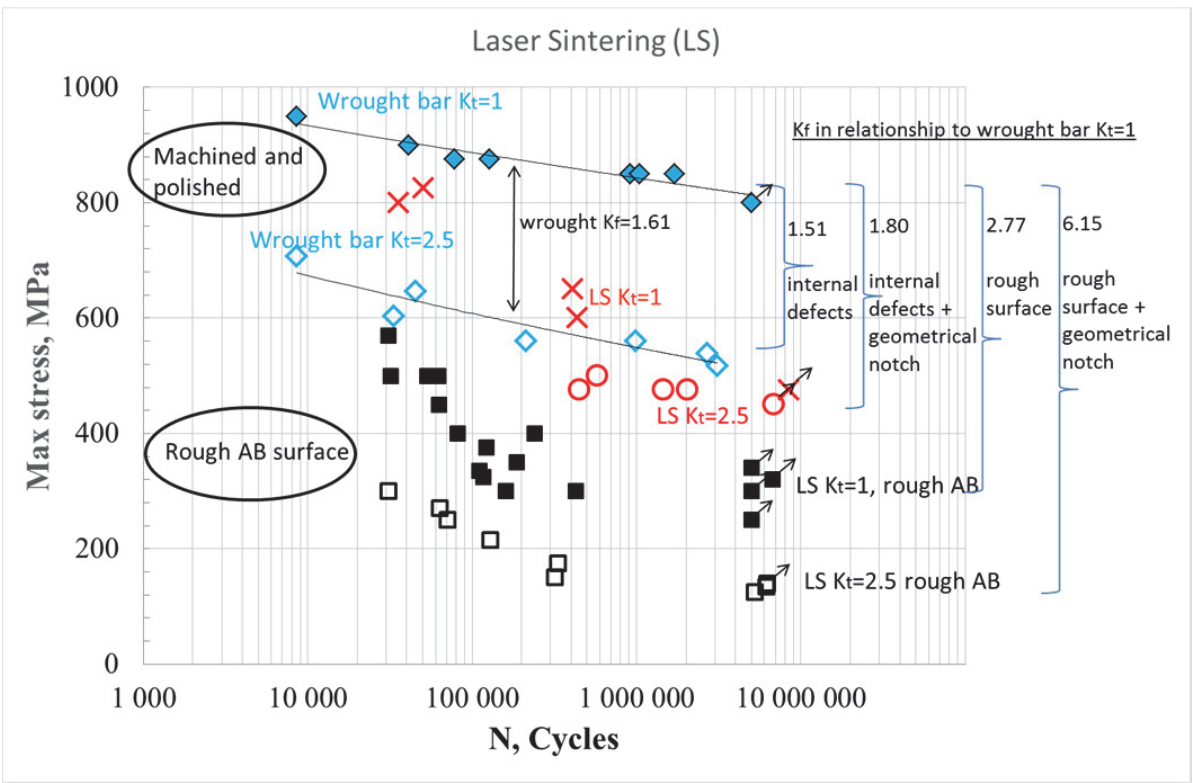

Figure 26. Fatigue notch factor, $\mathrm{K}_{\mathrm{f}}$, for LS material compared to wrought material. $\mathrm{K}_{\mathrm{t}}=$ Stress concentration factor. $\mathrm{AB}=$ as-built surface. Graph from paper I.

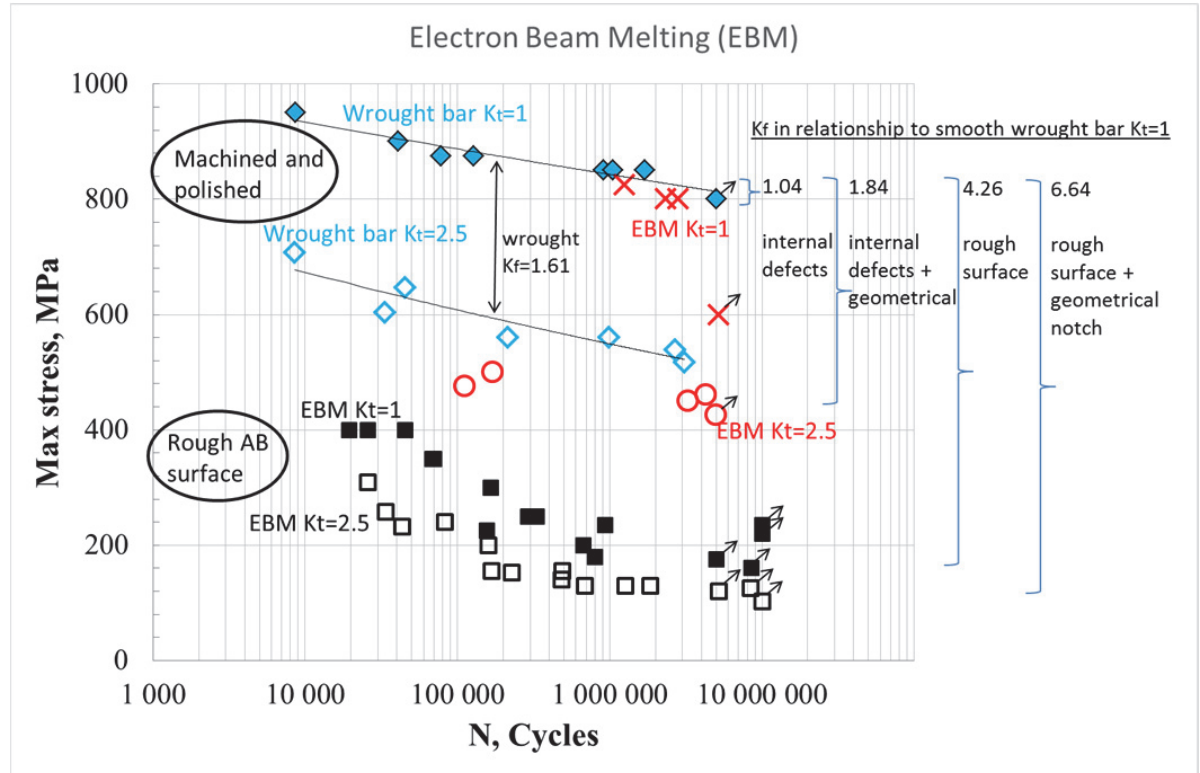

Figure 27. Fatigue notch factor, $\mathrm{K}_{\mathrm{f}}$, for EBM material compared to wrought material. $\mathrm{K}_{\mathrm{t}}=$ Stress concentration factor. $\mathrm{AB}=$ as-built surface. Graph from paper $\mathrm{I}$. 


\subsection{Notch Sensitivity}

Chan et al. [12] has determined the local stress concentration, $\mathrm{K}_{\mathrm{t}}$, at typical asbuilt surface crack initiation locations, as discussed in the previous section. If the stress concentrations from Chan et al. is combined with the fatigue notch factor determined in the present study, the notch sensitivity, q, which is given in Eq. 3 [49] can be determined for both LS and EBM material with rough as-built surfaces, see Table 10 .

$$
q=\frac{K_{f}-1}{K_{t}-1}
$$

Table 10. Notch sensitivity, q, determined from the stress concentration factor, $\mathrm{K}_{\mathrm{t}}$, and the fatigue notch factor, $\mathrm{K}_{\mathrm{f}}$, for $\mathrm{AM}$ material with rough as-built $(\mathrm{AB})$ surfaces. Machined wrought bar is given as a reference.

\begin{tabular}{|l|l|l|l|}
\hline Material & $\mathbf{K}_{\mathrm{t}}$ & $\mathbf{K}_{\mathbf{f}}$ & $\mathbf{q}$ \\
\hline LS AB surface & $5.4[12]$ & $2.8^{*}$ & 0.4 \\
\hline EBM, AB surface & $9.1[12]$ & $4.3^{*}$ & 0.4 \\
\hline $\begin{array}{l}\text { Wrought bar with machined notch } \\
\text { (reference) }\end{array}$ & 2.5 & $1.6^{* *}$ & 0.4 \\
\hline
\end{tabular}

$* \mathrm{~K}_{\mathrm{t}}=1$ (type 1) specimen, ${ }^{* *} \mathrm{~K}_{\mathrm{t}}=2.5$ (type 2 ) specimen

The notch sensitivity, q, in Table 10 appears to be equal for EBM and LS material with rough as-built surfaces and wrought bar with machined surface even though the fatigue behaviour differs greatly.

\subsection{Variable Amplitude Fatigue}

Prior to this study, there have been no previously published studies, to our knowledge, on variable amplitude fatigue behaviour for any AM metal material, Ti6Al4V included. This is not unexpected since a lot of variable amplitude fatigue testing is company specific and performed in-house at companies, hence the low number of publications. Moreover, the focus in academia for AM research has so far been primarily on fundamental material behaviour at the expense of applied research like variable amplitude fatigue testing.

\subsubsection{Predicted Fatigue Life}

The fatigue life for specimens, both with (type 2) and without (type 1) geometrical notches, has been predicted with a critical cumulative damage sum $D=1$ for fatigue loading with the variable amplitude load sequence Short-FALSTAFF. The predictions are presented in Figure 29 and Figure 30 and the predicted 
maximum net section peak stress that correspond to 15000 simulated flights for each test series was then further used for fatigue testing.

\subsubsection{Experimental Results Compared to Predictions}

The fatigue test results with the Short-FALSTAFF variable amplitude load sequence are in good agreement with the predicted fatigue life for all test series as illustrated by Table 11 and Figure 28, in which an experimental fatigue life exceeding 15000 simulated flights generates a $\mathrm{D}>1.0$. However, even though in good agreement to the predictions, the experimental fatigue life was generally slightly underestimated resulting in an average experimental cumulative damage of $\mathrm{D} \geq 1.0$ for all test series which is presented in Table 11 .

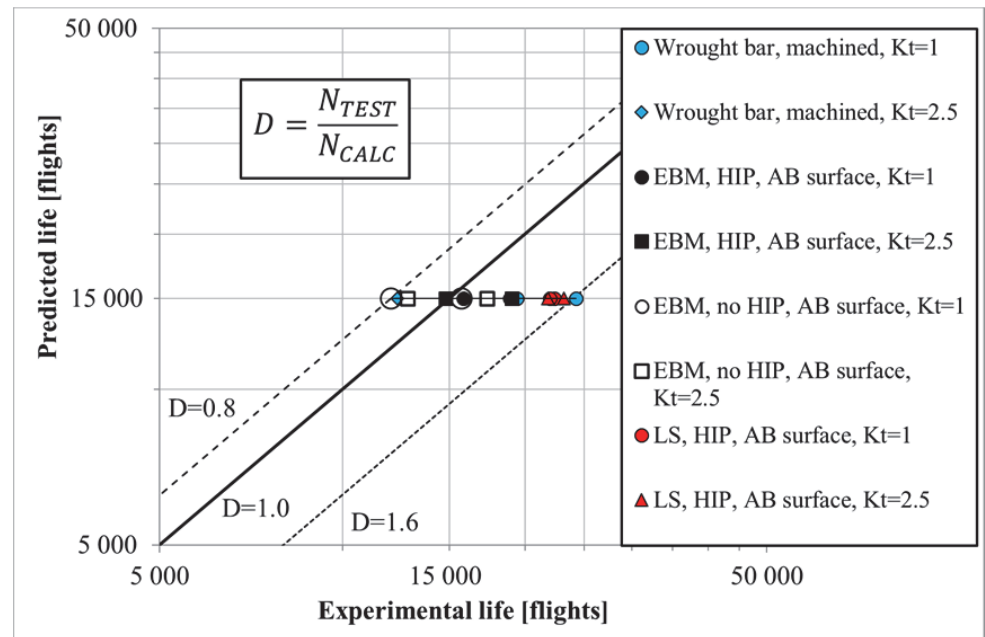

Figure 28. Predicted fatigue life compared to experimental results. Graph from paper II.

Table 11. Average fatigue life and corresponding cumulative damage. $\mathrm{K}_{\mathrm{t}}=1$ (type 1 ) and $\mathrm{K}_{\mathrm{t}}=2.5$ (type 2) specimens are combined in the evaluation. LS and EBM specimens had rough as-built surface while the wrought specimens had machined surfaces.

\begin{tabular}{|c|c|c|c|}
\hline Material & $\begin{array}{l}\text { Average } \\
\text { fatigue } \\
\text { life } \\
\text { [flights] } \\
\end{array}$ & $\begin{array}{l}\text { Average exper- } \\
\text { imental cumu- } \\
\text { lative damage, } \\
\text { D }\end{array}$ & $\begin{array}{l}\text { Range of ex- } \\
\text { perimental } \\
\text { cumulative } \\
\text { damage, D }\end{array}$ \\
\hline Predicted fatigue life, all series & 15000 & N/A & $\mathrm{N} / \mathrm{A}$ \\
\hline Wrought bar & 17950 & 1.2 & $0.8-1.6$ \\
\hline LS (HIP) * & 22320 & 1.5 & 1.5 \\
\hline EBM (HIP) & 17125 & 1.1 & $1.0-1.3$ \\
\hline EBM (no HIP) & 14470 & 1.0 & $0.8-1.2$ \\
\hline EBM (both HIP and no HIP) & 15800 & 1.1 & $0.8-1.3$ \\
\hline
\end{tabular}

* All specimens had similar fatigue life, i.e. no scatter 


\subsubsection{Effect of Hot Isostatic Pressing (HIP)}

The EBM material was tested both with and without HIP treatment and no distinct difference can be seen between the two conditions, see Figure 29 and Figure 30 , even though there are tendencies that the non-HIP samples without geometrical notches (type $1, \mathrm{~K}_{\mathrm{t}}=1$ ) had slightly shorter fatigue life. This behaviour can be related to the discussion in section 7.2, in which non-HIP samples had an apparent lower fatigue strength due to a $5 \%$ smaller load bearing area due to a considerable amount of internal defects in the fracture surface. The same theory applies for the variable amplitude test results, in which a re-calculation of the maximum net section peak stress with a 5\% smaller cross-section area, would result in non-HIP fatigue life in line with the HIP:ed samples.

Moreover, since this tendency only can be seen for un-notched samples without HIP, this correspond well with the discussion in section 7.3. The notched specimens (type $2, \mathrm{~K}_{\mathrm{t}}=2.5$ ) will have failure starting from a location, in the notch, with an average severity in the local stress concentration while the un-notched (type 1 , $\mathrm{K}_{\mathrm{t}}=1$ ) specimens will have cracks starting from the most severe surface or internal defect in the gauge section of the specimen. Hence, the notched samples, with rough as-built surface, will have more similar behaviour regardless of HIP or not compared to the un-notched samples. 


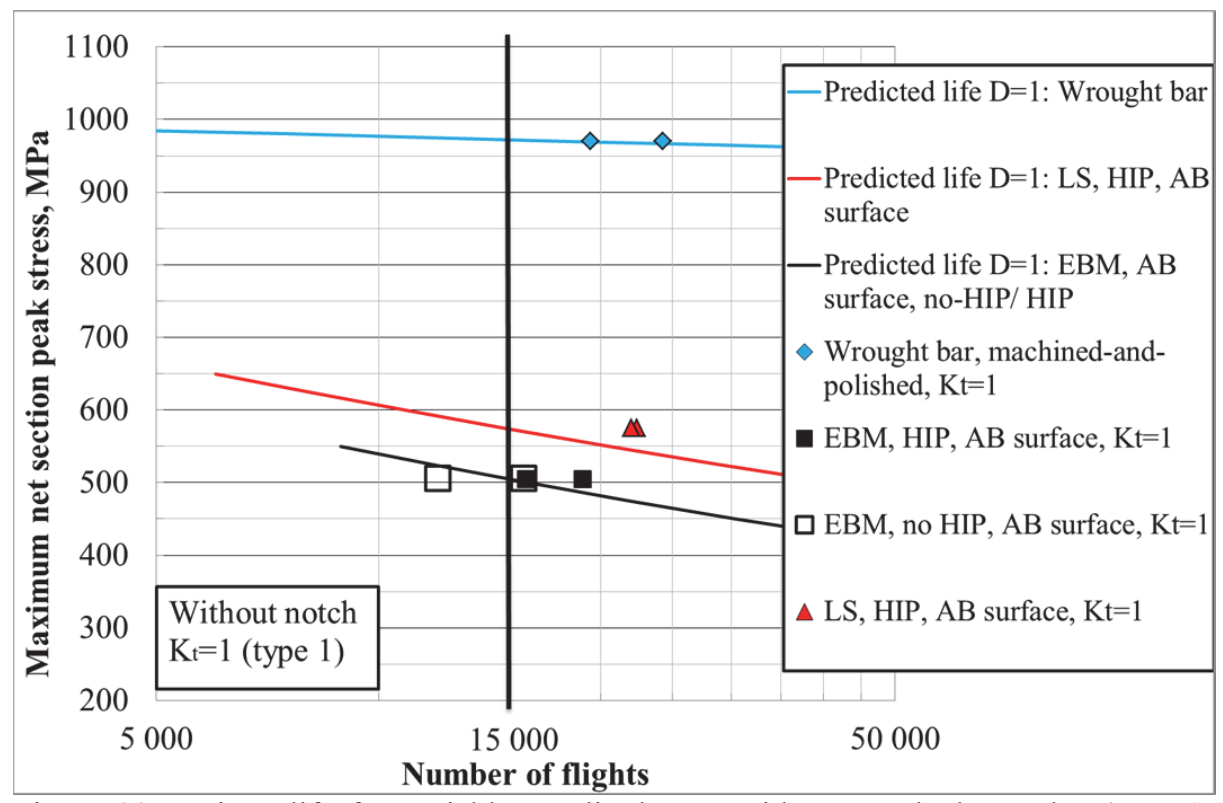

Figure 29. Fatigue life for variable amplitude test with un-notched samples (type 1, $\mathrm{K}_{\mathrm{t}}=1$ ). $\mathrm{AB}=$ as-built, $\mathrm{HIP}=$ Hot Isostatic Pressing. Graph from paper II.

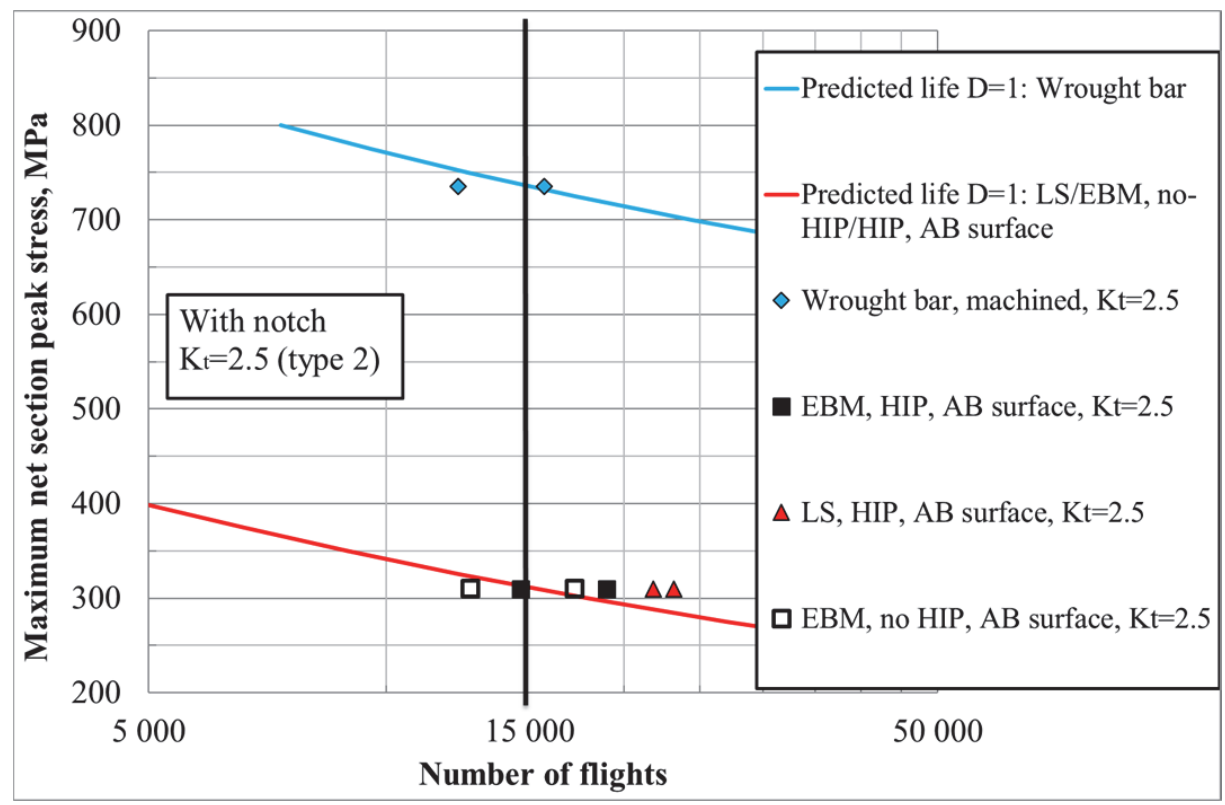

Figure 30. Fatigue life for variable amplitude test with notched samples (type 2, $\left.\mathrm{K}_{\mathrm{t}}=2.5\right) . \mathrm{AB}=$ as-built, $\mathrm{HIP}=$ Hot Isostatic Pressing. Graph from paper II. 


\section{SUMMARY OF INCLUDED PAPERS}

\section{Paper I: Fatigue behaviour of notched additive manufactured Ti6Al4V with as-built surfaces}

In this study, titanium alloy Ti6Al4V produced by the Additive Manufacturing (AM) processes Electron Beam Melting (EBM) and Laser Sintering (LS) were investigated. The main purpose of this paper was to determine the effect on constant amplitude fatigue properties for combinations of rough as-built AM surface and geometrical notches built directly by AM. Furthermore, the effect of Hot Isostatic Pressing (HIP) treatment on specimens with rough as-built surface was investigated.

The rough surface was found to be the single most severe factor for materials with rough as-built surfaces. Consequently, the fatigue strength for materials with a rough as-built surface were approximate $65-75 \%$ lower than for conventional produced material and a geometrical notch in combination with a rough asbuilt surface reduced the fatigue strength even more. HIP treatment did not give any improvement in fatigue life for samples with rough as-built surfaces since the fatigue behaviour will be dominated by the local stress concentrations at the rough surface rather than by internal defects.

\section{Paper II: Fatigue behaviour of additive manufactured Ti6Al4V, with as-built surfaces, exposed to variable amplitude loading}

The purpose of this study was to investigate the variable amplitude fatigue behaviour for Ti6Al4V, with rough as-built surfaces, manufactured with Additive Manufacturing (AM). Material produced with the AM processes Electron Beam Melting (EBM) and Laser Sintering (LS) was investigated using both notched and un-notched specimens. The fatigue life was predicted for variable amplitude load sequence Short-FALSTAFF (Fighter Aircraft Loading STAndard For Fatigue) using constant amplitude fatigue data and a cumulative damage approach. Variable amplitude testing was performed and the predicted and experimental fatigue life showed good agreement, even though a majority of the experimental results slightly exceeded the predicted life. Furthermore, Hot Isostatic Pressing (HIP) treatment had negligible enhancing effect on the fatigue properties for material with rough as-built surfaces. 


\section{CONCLUSIONS}

The research presented in this licentiate thesis deals with the fatigue behaviour of the titanium alloy Ti6Al4V produced with the Additive Manufacturing (AM) processes Laser Sintering (LS) and Electron Beam Melting (EBM). The studies in this thesis has been focused on determining the fatigue properties of material with rough as-built AM surfaces and the combined fatigue behaviour of geometrical notches with rough as-built surfaces. It was found that the rough as-built surface was the single most severe factor for fatigue. The rough as-built surface alone resulted in a fatigue notch factor, $\mathrm{K}_{\mathrm{f}}$, of 2.8 for LS material and 4.3 for EBM material, which correspond to $65-75 \%$ reduction in fatigue strength.

Few aircraft parts have, however, simple flat geometries and the effect of stress concentrations like corners or radii of curvature need to be considered. AM specimens with geometrical notches with rough as-built surfaces were investigated and resulted in fatigue notch factors of $\mathrm{K}_{\mathrm{f}}=6.2$ for LS and $\mathrm{K}_{\mathrm{f}}=6.6$ for EBM in relation to smooth specimens of wrought bar material. The notch sensitivity, q, was found to be equal for LS and EBM material with rough as-built surface and machined wrought material.

Furthermore, the constant amplitude fatigue data and cumulative damage calculations were used to predict the fatigue life for the variable amplitude load sequence Short-FALSTAFF (Fighter Aircraft Loading STAndard For Fatigue) which is a tensile dominated load spectrum. Cumulative damage calculations were used to predict a load level corresponding to 15000 simulated flights which were further used for variable fatigue testing. The predicted fatigue life was overall consistent to the experimental results, even though most experiments slightly exceeded the predicted life. Consequently, a cumulative damage approach can therefore be used, at least for tensile dominated load sequences, to predict the fatigue life for variable amplitude loaded Ti6Al4V structures manufactured by AM.

Neither constant nor variable amplitude loading showed any significant improvement in fatigue life for material subjected to Hot Isostatic Pressing (HIP) treatment for specimens with rough as-built surfaces. The conclusion is that the fatigue behaviour will be dominated by the rough as-built surface rather than by defects inside the material.

Finally, to fully be able to use the potential of AM in aerospace applications, the fatigue properties need to be improved by further work to reduce the surface roughness, either by process parameter optimization or by post processing. 


\section{BIBLIOGRAPHY}

[1] Council A, Petch M. 3D Printing: Rise of the Third Industrial Revolution. 2014.

[2] Frazier WE. Metal additive manufacturing: A review. J Mater Eng Perform 2014;23:1917-28

[3] Horn TJ, Harrysson OLA. Overview of current additive manufacturing technologies and selected applications. Sci Prog 2012;95:255-82.

[4] Hällgren S, Pejryd L, Ekengren J. Additive Manufacturing and High Speed Machining -Cost comparison of short lead time manufacturing methods. Procedia CIRP 2016;50:384-9.

[5] Lewandowski JJ, Seifi M. Metal Additive Manufacturing: A Review of Mechanical Properties. Annu Rev Mater Res 2016;46:151-86.

[6] Arcam AB n.d. www.arcam.com (accessed February 16, 2017).

[7] EOS n.d. www.eos.info (accessed February 16, 2017).

[8] Concept Laser n.d. www.concept-laser.de (accessed February 16, 2017).

[9] SLM Solutions n.d. www.slm-solutions.com (accessed February 16, 2017).

[10] Renishaw n.d. www.renishaw.com, (accessed February 16, 2017).

[11] Edwards P, O'Conner A, Ramulu M. Electron Beam Additive Manufacturing of Titanium Components: Properties and Performance. J Manuf Sci Eng 2013;135:61016.

[12] Chan KS, Koike M, Mason RL, Okabe T. Fatigue life of titanium alloys fabricated by additive layer manufacturing techniques for dental implants. Metall Mater Trans A Phys Metall Mater Sci 2013;44:1010-22.

[13] Rafi HK, Karthik N V., Gong H, Starr TL, Stucker BE. Microstructures and mechanical properties of Ti6A14V parts fabricated by selective laser melting and electron beam melting. J Mater Eng Perform 2013;22:3872-83.

[14] Mangano C, Piattelli A, D’Avila S, Iezzi G, Mangano F, Onuma T, et al. Early human bone response to laser metal sintering surface topography: a histologic report. vol. 36. 2010.

[15] Edwards P, Ramulu M. Fatigue performance evaluation of selective laser melted Ti-6Al-4V. Mater Sci Eng A 2014;598:327-37. 
[16] Murr LE, Gaytan SM, Ramirez DA, Martinez E, Hernandez J, Amato KN, et al. Metal Fabrication by Additive Manufacturing Using Laser and Electron Beam Melting Technologies. J Mater Sci Technol 2012;28:1-14.

[17] Carpenter C. Additive Manufacturing - Additive Manufacturing for the Space Industry. CRC Press; 2015.

[18] Uriondo A, Esperon-Miguez M, Perinpanayagam S. The present and future of additive manufacturing in the aerospace sector: A review of important aspects. Proc Inst Mech Eng Part G J Aerosp Eng 2015;229:2132-47.

[19] Majumdar JD, Manna I, editors. Laser-Assisted Fabrication of Materials. vol. 161. Berlin, Heidelberg: Springer Berlin Heidelberg; 2013.

[20] Younossi O, Seong S, Goldsmith BW. Titanium Industrial Base, Price Trends, and Technology Initiatives. 2009.

[21] Kasperovich G, Hausmann J. Improvement of fatigue resistance and ductility of TiAl6V4 processed by selective laser melting. J Mater Process Technol 2015;220:202-14.

[22] Greitemeier D, Palm F, Syassen F, Melz T. Fatigue performance of additive manufactured TiAl6V4 using electron and laser beam melting. Int $\mathrm{J}$ Fatigue 2017;94:211-7.

[23] Greitemeier D, Holzinger V, Donne CD, Eufinger J, Melz T. Fatigue prediction of additive manufactured Ti-6Al-4V for aerospace: Effect of defects, surface roughness. 28th ICAF Symp - Helsinki, 3-5 June 2015, Report-NoTX2-2015$1202015: 3-5$.

[24] Algardh JK, Horn T, West H, Aman R, Snis A, Engqvist H, et al. Thickness dependency of mechanical properties for thin-walled titanium parts manufactured by Electron Beam Melting (EBM)®. Addit Manuf 2016;12:45-50.

[25] Donachie MJ. Titanium : A Technical Guide. 2nd ed. 2000.

[26] Svensson M, Ackelid U, Ab A. Titanium Alloys Manufactured with Electron Beam Melting Mechanical and Chemical Properties. Med. Device Mater. V Proc. from Mater. Process. Med. Devices Conf. 2009, 2009, p. p 189-194.

[27] Cain V, Thijs L, Van Humbeeck J, Van Hooreweder B, Knutsen R. Crack propagation and fracture toughness of Ti6Al4V alloy produced by selective laser melting. Addit Manuf 2014;5:68-76.

[28] Simonelli M, Tse YY, Tuck C. Effect of the build orientation on the mechanical properties and fracture modes of SLM ti-6Al-4V. Mater Sci Eng A 2014;616:111. 
[29] Liu QC, Elambasseril J, Sun SJ, Leary M, Brandt M, Sharp PK. The Effect of Manufacturing Defects on the Fatigue Behaviour of Ti-6Al-4V Specimens Fabricated Using Selective Laser Melting. Adv Mater Res 2014;891-892:151924.

[30] Bauza MB, Moylan SP, Panas RM, Burke SC, Martz E, Taylor JS, et al. Study of accuracy of parts produced using additive manufacturing Carl Zeiss Industrial Metrology truss. 2014 ASPE Spring Top Meet Dimens Accuracy Surf Finish Addit Manuf Berkeley, CA, United States April 13, 2014 through April 2014:34. doi:LLNL-CONF-651802.

[31] de Formanoir C, Michotte S, Rigo O, Germain L, Godet S. Electron beam melted Ti-6Al-4V: Microstructure, texture and mechanical behavior of the as-built and heat-treated material. Mater Sci Eng A 2016;652:105-19.

[32] Eriksson R. Thermal Barrier Coatings: Durability Assessment and Life Prediction. Dissertation No. 1527, Linköping University; 2013.

[33] Joint publication of Flugzeugwerke Emmen, Switzerland; Laboratorium für Betriebsfestigkeit (LBF), Germany; National Aerospace Laboratory (NLR), Netherlands; and Industrie-Anlagen-Betriebsgesellschaft $\mathrm{mbH}$ (IABG) $\mathrm{G}$. FALSTAFF: Description of a fighter aircraft loading standard for fatigue evaluation. 1976.

[34] CEAT Report M7681900, Centre d'Essais Aeronautique de Toulouse, Toulouse. 1980.

[35] Sunder R. Contribution of Individual Load Cycles to Crack Growth under Aircraft Spectrum Loading. STP1122 Adv. Fatigue Lifetime Predict. Tech., ASTM; 1992, p. $176-90$.

[36] Cardrick, A. W. , Perrett BHE. Fatigue tests on plain specimens of titanium 6Al4V under variable amplitude loading. Aeronaut Res Counc CP 1276, 1974.

[37] Palmgren AG. Die Lebensdauer von Kugellagern. Zeitschrift Des Vereines Dtsch Ingenieure 1924;68:339-41.

[38] Miner MA. Cumulative damage in fatigue. J Appl Mech 1945;12:159-64.

[39] Facchini L, Magalini E, Robotti P, Molinari A. Microstructure and mechanical properties of Ti-6Al-4V produced by electron beam melting of pre-alloyed powders. Rapid Prototyp J 2009;15:171-8.

[40] Leuders S, Thöne M, Riemer A, Niendorf T, Tröster T, Richard H a., et al. On the mechanical behaviour of titanium alloy TiAl6V4 manufactured by selective laser melting: Fatigue resistance and crack growth performance. Int $\mathrm{J}$ Fatigue 2013;48:300-7.

[41] Leuders S, Lieneke $T$, Lammers $S$, Tröster $T$, Niendorf $T$. On the fatigue properties of metals manufactured by selective laser melting - The role of ductility. J Mater Res 2014:1-9. 
[42] Chan KS. Characterization and analysis of surface notches on Ti-alloy plates fabricated by additive manufacturing techniques. Surf Topogr Metrol Prop 2015;3:44006.

[43] Cronskär M, Bäckström M, Rännar L-E. Production of customized hip stem prostheses - a comparison between conventional machining and electron beam melting (EBM). Rapid Prototyp J 2013;19:365-72.

[44] Karlsson J. Optimization of Electron Beam Melting for Production of Small Components in Biocompatible Titanium Grades. Disseratation No. 1206, Uppsala University; 2015.

[45] Wycisk E, Emmelmann C, Siddique S, Walther F. High Cycle Fatigue (HCF) Performance of Ti-6Al-4V Alloy Processed by Selective Laser Melting. Adv Mater Res 2013;816-817:134-9.

[46] Hrabe N, Gnäupel-Herold T, Quinn T. Fatigue properties of a titanium alloy (Ti$6 \mathrm{Al}-4 \mathrm{~V})$ fabricated via electron beam melting (EBM): Effects of internal defects and residual stress. Int J Fatigue 2017;94:202-10.

[47] Gong H, Rafi K, Starr T, Stucker BE. Effect of Defects on Fatigue Tests of AsBuilt Ti-6Al-4V Parts Fabricated by Selective Laser Melting. Proc. Solid Free. Fabr. Symp., 2012, p. 499-506.

[48] Wycisk E, Solbach A, Siddique S, Herzog D, Walther F, Emmelmann C. Effects of Defects in Laser Additive Manufactured Ti-6Al-4V on Fatigue Properties. Phys Procedia 2014;56:371-8.

[49] Theodore N. High Cycle Fatigue: A Mechanics of Materials Perspective. 1st ed. Elsevier Ltd; 2006. 


\section{Papers}

The articles associated with this thesis have been removed for copyright reasons. For more details about these see:

http://urn.kb.se/resolve? urn:nbn:se:liu:diva-137233 